This is a preprint of a paper published as:

Van Steen, C., Nasser, H., Verstrynge, E., Wevers, M. (2021).

Acoustic emission source characterisation of chlorideinduced corrosion damage in reinforced concrete. Structural Health Monitoring. Advance online publication.

Original DOI: 10.1177/14759217211013324 


\title{
Acoustic emission source characterisation of chloride-induced corrosion damage in reinforced concrete
}

\author{
Charlotte Van Steen ${ }^{1}$, Hussein Nasser ${ }^{1}$, Els Verstrynge ${ }^{1}$, and Martine Wevers ${ }^{2}$
}

\begin{abstract}
Worldwide, asset managers are struggling with the management of aging infrastructure in reinforced concrete (RC). Early detection of reinforcement corrosion, which is generally considered as the major problem, can help to perform dedicated maintenance and repair. The acoustic emission (AE) technique is promising to reach this goal, however, research on the characterisation of the different damage sources during corrosion in RC remains scarce. In this paper, the characterisation of damage processes is investigated on small RC prisms and upscaled to RC beams under accelerated conditions in a laboratory environment. Damage sources are assigned based on careful validation with crack width measurements and dummy samples. Signals originating from different AE sources are compared in the time and frequency domain. Moreover, the continuous wavelet transform (WT) is applied to provide information on time-frequency characteristics. The results show that the moment of concrete macro-cracking can be derived from a sudden increase of the cumulative $A E$ events and cumulative AE energy. However, validation with crack measurements is required. The shift in both peak and centre frequency of the AE signals is found to be a better indicator. WT allows to distinguish $\mathrm{AE}$ sources when frequency ranges are overlapping. Possible $\mathrm{AE}$ sources, e.g. the corrosion process and concrete cover cracking, are successfully assigned. The major contributions of this paper are the characterization of $\mathrm{AE}$ sources from corrosion damage in RC, and validation with crack measurements, dummy samples as well as a dedicated wavelet analysis.
\end{abstract}

\section{Keywords}

acoustic emission, reinforcement corrosion, source characterisation, wavelet analysis, sensor type

\section{Introduction}

Corrosion of the reinforcement seriously threatens the durability and structural safety of our existing reinforced concrete (RC) structures. The passive layer protecting the rebar is easily destroyed by carbonation and/or the presence of chlorides. Steel dissolves and turns into expansive corrosion products. On the one hand, this causes a reduction of the cross section of the rebar. On the other hand, as the corrosion products occupy a larger volume than the original steel, internal tensile stresses in the concrete will build up. This will eventually result in cracking and spalling of the concrete cover. Both mechanisms will influence the bond at the reinforcement-concrete interface.

Currently, inspection of existing RC structures is mainly based on visual findings, core drilling, and electrochemical measurements ${ }^{1}$. Although visual inspection is straightforward, damage can only be detected once it has reached the surface. Core drilling is a destructive technique which only gives insight into the damage level of the zone where the core was taken, making it difficult to generalise the result towards the global condition of the structure. Electrochemical techniques are widely used, however, these techniques are unsuitable to monitor continuously and are dependent on climatic conditions (e.g. moisture content of the concrete $)^{2}$. To allow an enhanced and earlier assessment of ongoing deterioration processes, a proper combination of certain non-destructive techniques (NDT) and structural health monitoring (SHM) is powerful as it enables to assess the structural integrity in a non-invasive way, even when damage is not yet visible on the surface.

In the viewpoint of efficient inspection and early detection, the acoustic emission (AE) technique is an ideal choice as it allows non-destructive and continuous monitoring of the structure. The technique detects elastic waves originating from micro-structural changes inside a material ${ }^{3}$. The sound wave radiates from its origin, also called the AE source, and propagates in all directions as an elastic wave. When the wave reaches the surface, it causes small displacements which are detected by piezoelectric transducers attached to the surface of the material. The technique enables to both capture the corrosion process itself and the progress of concrete cover cracking ${ }^{3}$.

Many applications of AE monitoring during mechanical testing of corroded RC samples are reported in the literature $^{4-6}$, whereas AE monitoring during the (accelerated) corrosion process itself is less discussed. For reinforcement corrosion monitoring, different stages during the process can be distinguished, namely the initiation stage (before concrete

${ }^{1}$ Department of Civil Engineering, KU Leuven, Leuven, Belgium
${ }^{2}$ Department of Materials Engineering, KU Leuven, Leuven, Belgium

\section{Corresponding author:}

Charlotte Van Steen, Department of Civil Engineering, KU Leuven, 3001 Leuven, Belgium.

Email: charlotte.vansteen@kuleuven.be 
cracking) and the propagation stage (during concrete cracking $)^{7,8}$.

$\mathrm{AE}$ analysis in concrete structures is mainly based on $\mathrm{AE}$ parameters, which are a set of extracted features that describe the signal. Examples of AE parameters are amplitude, risetime, and duration. Unfortunately, parametric results are dependent on a threshold which is defined by the user before the start of the test. This makes it challenging to compare the results when different test setups are considered. Indeed, $\mathrm{AE}$ parameters such as rise-time, duration, and counts are influenced by this threshold. In addition, rebar corrosion is a very complex process which involves the interaction between different damage mechanisms. Therefore, several types of AE sources are present.

An advantage of the $\mathrm{AE}$ technique is that the characteristics of an AE signal depend on the source type. Therefore, different damage processes can be distinguished based on the underlying modal structure of an AE signal. Signal-based analysis, which makes use of the entire waveform instead of few parameters describing the signal, allows a more reliable interpretation of the different damage mechanisms. It would provide the ability to tell which source mechanism is present. Based on this information, maintenance and repair interventions can be planned. However, the transfer function of an $\mathrm{AE}$ signal that describes the transfer from source to acquisition, is influenced by many aspects such as the couplant, sensor and system, but also the propagation path of the signal ${ }^{9}$. Dedicated signal-based analysis can therefore be challenging.

Characterisation of $\mathrm{AE}$ sources during corrosion has been briefly discussed in the literature ${ }^{10,11}$. AE sources were assigned based on the peak frequency of the signals. In this paper, a more in depth wavelet analysis is performed to express the frequency spectrum in function of time to identify the characteristic features of $\mathrm{AE}$ signals ${ }^{12}$. This approach has been applied by Yoon et al. ${ }^{4}$ on corroded RC beams during four-point bending tests to distinguish between different stages during the test. However, it has not been performed so far during the (accelerated) corrosion process itself.

The research described in this paper aims to obtain a reliable and extensive dataset of $\mathrm{AE}$ monitoring during the corrosion process in $\mathrm{RC}$ as these datasets are still scarce in the literature. This paper aims to assign damage sources to $\mathrm{AE}$ signals recorded during accelerated corrosion in $\mathrm{RC}$ at two different sample scales. On a first sample scale, the $\mathrm{RC}$ prisms, different corrosion levels are targeted. Therefore, uncracked and cracked samples are obtained. On a second sample scale, the RC beams, the developed methodology is upscaled to larger samples. AE source characterisation is based on a range of dummy samples in which specific, isolated $\mathrm{AE}$ sources are present.

In a first part of the paper, an overview of the experimental program on RC prisms, RC beams, and dummy samples is given. Second, the AE post-processing methods are described. Third, general trends of the cumulative AE events and energy, and peak and centre frequencies of the signals are discussed for the accelerated corrosion tests of the RC prisms and beams. Fourth, AE source characterisation is performed by means of the dummy samples. Signals are compared in the time and frequency domain, and timefrequency characteristics are analysed. Finally, results are compared with literature findings and results from a test series with a different $\mathrm{AE}$ sensor type.

\section{Experimental test program}

\section{Accelerated corrosion of RC prisms}

Specimen preparation and material properties A first test series was performed on RC prisms. These prisms were part of a larger experimental program. After AE monitoring during the accelerated corrosion process, which is the focus of this paper, the RC prisms were subjected to pull-out tests to quantify the bond $\operatorname{loss}^{13}$. Prisms reinforced with a smooth rebar and prisms reinforced with a ribbed rebar were tested. The nominal diameter of both rebar types was 12 $\mathrm{mm}$. The embedded length was equal to $100 \mathrm{~mm}$. Three target corrosion levels, namely $1.5 \%, 5 \%$, and $10 \%$ mass loss, were compared for both the smooth and ribbed rebars. Six samples were continuously monitored with AE detection. The nomenclature of the samples is built as shown in figure 1 .

Only the middle part of the main rebar was bonded to the concrete. Polyvinyl chloride (PVC) tubes were used to avoid bonding of both rebar ends. A wooden mould with dimensions $150 \times 150 \times 250 \mathrm{~mm}^{3}$ was made in which the rebar was placed in the centre. To connect the power supply of the accelerated corrosion setup, the rebar was protruding from both sides.

Table 1 shows the concrete composition. An average cubic compressive strength of $55.04 \mathrm{MPa}$ (standard deviation (SD) 3.20 MPa) was obtained at 28 days according to EN 123903. The samples were cured for 28 days in a curing room $\left(20 \pm 1{ }^{\circ} \mathrm{C}, 95 \pm 3 \%\right.$ relative humidity (RH)). Afterwards, the specimens were fully immersed in a $5 \%$ sodium chloride solution. After three days, the samples were placed in the accelerated corrosion setup in a climatised room $\left(20 \pm 1^{\circ} \mathrm{C}\right.$, $60 \pm 3 \% \mathrm{RH})$. The accelerated corrosion process and $\mathrm{AE}$ monitoring started at a sample age of 31 days. Table 2 gives an overview of the samples and their specifications.

$$
\begin{aligned}
& \text { CL1-R1 } \\
& \qquad \begin{array}{l}
\llcorner \\
\quad \text { Sample number } \\
\text { Rebar type: smooth }(\mathrm{S}) \text { or ribbed }(\mathrm{R})
\end{array} \\
& \text { Corrosion level (CL) } 1,2 \text {, or } 3 \text { (i.e. } 1.5,5 \text {, or } 10 \% \text { mass loss) }
\end{aligned}
$$

Figure 1. Nomenclature of the RC prisms.

Table 1. Concrete composition.

\begin{tabular}{cc}
\hline Materials & $\mathrm{kg} / \mathrm{m}^{3}$ concrete \\
\hline CEM I 42.5N & 350 \\
Sand (0/5) & 620 \\
Aggregates (4/14) & 1270 \\
Water & 164 \\
Salt $(\mathrm{NaCl})$ & 7 \\
\hline
\end{tabular}

Accelerated corrosion setup A direct current was imposed to induce and accelerate the corrosion process. The current density was set to $100 \mu \mathrm{A} / \mathrm{cm}^{2}$ or $1.16 \mathrm{~mm} /$ year. The required current in $\mathrm{mA}$ can be calculated by multiplying the current density with the corroding area of the rebar. The 
Table 2. Sample specifications of the RC prims and RC beams.

\begin{tabular}{ccccc}
\hline Sample name & $\begin{array}{c}\text { Target corrosion level } \\
{[\% \text { mass loss] }}\end{array}$ & Rebar type & $\begin{array}{c}\text { Corroding length } \\
{[\mathrm{mm}]}\end{array}$ & $\begin{array}{c}\text { Number of } \\
\text { AE sensors }\end{array}$ \\
\hline CL1-R1 & 1.5 & Ribbed & 100 & 2 \\
CL2-R1 & 5 & Ribbed & 100 & 2 \\
CL3-R1 & 10 & Ribbed & 100 & 2 \\
CL1-S1 & 1.5 & Smooth & 100 & 2 \\
CL2-S1 & 5 & Smooth & 100 & 2 \\
CL3-S1 & 10 & Smooth & 100 & 2 \\
\hline B10R1 & 10 & Ribbed & 1500 & 4 \\
B10R2 & 10 & Ribbed & 1500 & 4 \\
\hline
\end{tabular}

rebar acts as an anode and was therefore connected to the positive side of the power supply. The cathode, in this case a stainless steel plate, was connected to the negative side. The specimens were partially immersed in a $5 \%$ sodium chloride solution during exposure to ensure electrical connectivity and chloride ingress.

Figure 2 shows the accelerated corrosion setup. The corrosion process was interrupted every week in order to measure the cracks with a crack meter. The accuracy of the crack measurements was $0.05 \mathrm{~mm}$. Additionally, every side of the specimen was visually inspected and photographed.

Faraday's law was applied to estimate the duration of the accelerated corrosion process for each target corrosion level. Respectively 14,47 , and 94 days were needed to reach corrosion levels 1,2 , and 3.

Acoustic emission monitoring Broadband piezoelectric sensors with a flat frequency response between 100 and 400 $\mathrm{kHz}$ were attached on top of the specimen surface with hot melt glue. The AE sensors were connected to preamplifiers with a fixed gain of $34 \mathrm{~dB}$. The preamplifiers are in turn connected to a Vallen AMSY-6 acquisition system. Both AE parameters and waveforms were stored on a $\mathrm{PC}$ during the monitoring period. The data was visualised in real time with the Vallen VisualAE software. Further data processing was performed in Matlab.

All samples were monitored with two sensors placed on top of the sample with a linear distance of $100 \mathrm{~mm}$ (equal to the corroding rebar length), allowing localisation in 1D. In previously performed experimental work on a smaller sample scale ${ }^{14}$, a similar setup was used and it was proven that the $\mathrm{AE}$ technique was able to record the $\mathrm{AE}$ signals originating from the bottom part of the sample. Therefore, this setup was upscaled to the current test setup. Moreover, three samples could be monitored at the same time with the six-channel AE system.

The amplitude threshold was set to $40 \mathrm{~dB}$ to avoid false detections due to background noise. This threshold was experimentally determined by monitoring environmental noise before the start of the test. However, it was found that electromagnetic interference due to the presence of fluorescent lamps was still captured as their amplitude could reach $55 \mathrm{~dB}$. In order not to miss important lowamplitude signals, it was decided to set the threshold to 40 $\mathrm{dB}$ and eliminate signals due to electromagnetic interference afterwards. This fixed threshold was used to determine the time of arrival (TOA) in order to discretise different $\mathrm{AE}$ signals and store them together with a pre-trigger part. The pre-trigger time, duration discrimination time, and rearm time were set to $20 \mu \mathrm{s}, 400 \mu \mathrm{s}$, and $400 \mu \mathrm{s}$ respectively. The sampling rate was set to $10 \mathrm{MHz}$ and the length of the stored signal was $204.8 \mu$ s.

\section{Accelerated corrosion of $R C$ beams}

Specimen preparation A series of RC beams with dimensions $150 \times 200 \times 1800 \mathrm{~mm}^{3}$ were cast ${ }^{15}$. They were reinforced with one smooth or ribbed rebar and corroded up to three target corrosion levels. Two beams with a target corrosion level of $10 \%$ mass loss and reinforced with a ribbed rebar having a nominal diameter of $14 \mathrm{~mm}$, referred to as B10R1 and B10R2, were monitored during the first weeks of the corrosion process with the $\mathrm{AE}$ technique and will be discussed in this paper (see table 2). The rebar had a total length of $2000 \mathrm{~mm}$ of which $1500 \mathrm{~mm}$ was exposed to corrosion. The concrete cover was $30 \mathrm{~mm}$. The concrete composition was the same as for the RC prisms. The beams were placed in a curing room $\left(20 \pm 1{ }^{\circ} \mathrm{C}\right.$, $95 \pm 3 \% \mathrm{RH})$ for 28 days. Afterwards, the beams were moved to a climatised room $\left(20 \pm 1^{\circ} \mathrm{C}, 60 \pm 3 \% \mathrm{RH}\right)$ where the accelerated corrosion process and $\mathrm{AE}$ monitoring were started at a sample age of 29 days.

Accelerated corrosion setup The same principle as for the $\mathrm{RC}$ prisms was used to accelerate the corrosion process. However, instead of immersing the beams partially in the sodium chloride solution, the beams were placed upsidedown and a bottomless wooden tank with a length of 1250 $\mathrm{mm}$ was placed on top of the samples and sealed with silicone. The 5\% sodium chloride solution was added in this tank. The beams were corroded with a current density of $50 \mu \mathrm{A} / \mathrm{cm}^{2}$. The accelerated corrosion setup is shown in figure 3. Every week, a visual inspection was carried out and crack width measurements were performed with a crack meter (accuracy $0.05 \mathrm{~mm}$ ).

Acoustic emission monitoring A 2D sensor layout was used to monitor the beams continuously (figure 3). Four sensors were attached to the concrete. The distance between the sensors along the length of the beam was 750 and $500 \mathrm{~mm}$ for $\mathrm{B} 10 \mathrm{R} 1$ and $\mathrm{B} 10 \mathrm{R} 2$ respectively. The same AE sensors and acquisition system as during the experiments on the RC prisms were used. The threshold was $40 \mathrm{~dB}$. The pre-trigger time, duration discrimination time, and rearm time were set to $200 \mu \mathrm{s}, 450 \mu \mathrm{s}$, and $5000 \mu \mathrm{s}$ respectively. The sampling 


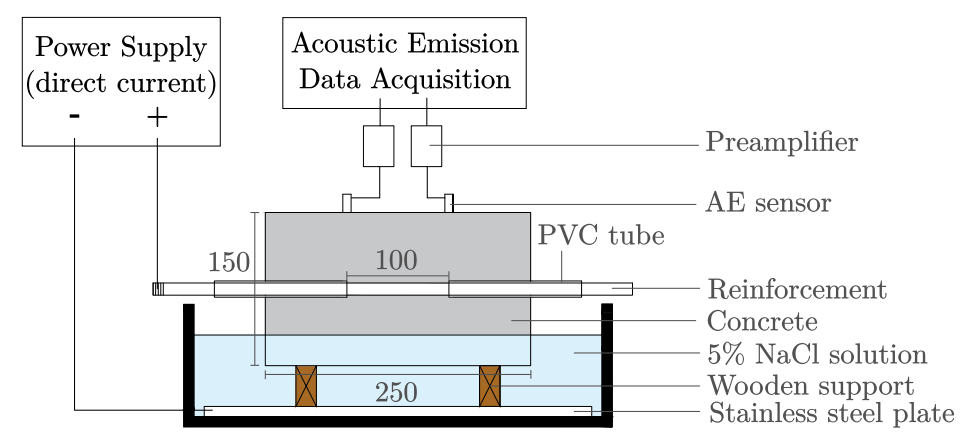

Figure 2. Schematic representation of the accelerated corrosion setup of the RC prisms, in mm.
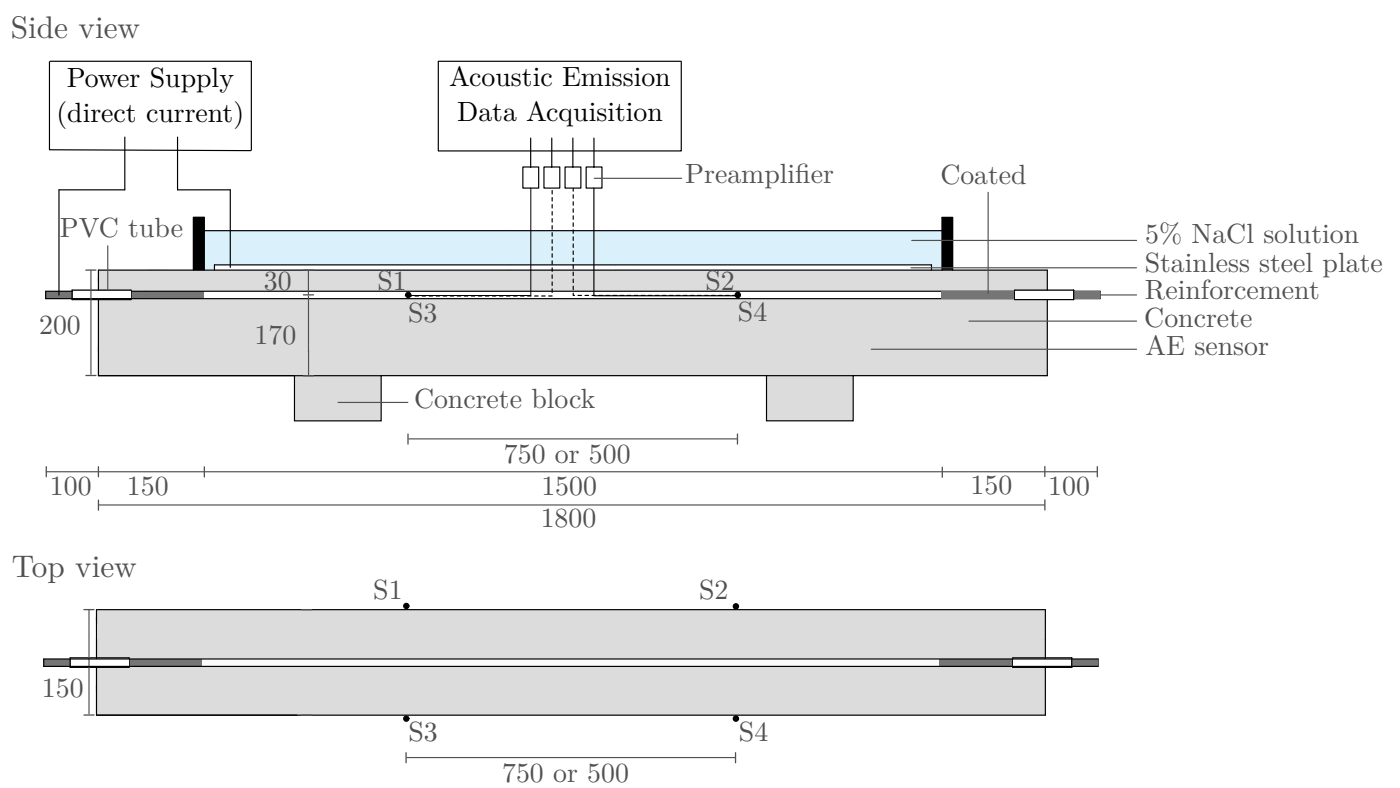

Figure 3. Schematic representation of the accelerated corrosion setup and $2 \mathrm{D} A E$ sensor configuration of the $\mathrm{RC}$ beams, in mm.

rate was set to $5 \mathrm{MHz}$ and the length of the stored signal was $819.2 \mu \mathrm{s}$.

\section{AE monitoring of dummy samples}

A set of dummy samples in which specific AE sources were isolated, was tested to characterise the different AE sources. Table 3 gives an overview of the different dummy samples that were tested and the possible processes that can occur in these samples. The dummy samples can be divided in three groups: (1) tests on rebars only, (2) tests on concrete prisms, and (3) a three-point bending test on a concrete beam. In the first group, rebars with a length of $30 \mathrm{~cm}$ were monitored with two sensors, one at each end of the rebar. In the second group, concrete prisms were monitored with 2 sensors on top (same layout as previously discussed for the $\mathrm{RC}$ prisms). None of the dummy samples of the second group showed concrete cracking. Typical signals originating from concrete cracking were investigated on an uncorroded RC beam that was subjected to a three-point bending test (group 3 ). The sensor closest to the bending crack was used for data analysis. In all samples, electromagnetic interference is likely to occur due to the presence of fluorescent lamps in the lab as discussed in ${ }^{16}$. All dummy samples were monitored with the same sensors as used during the corrosion tests (flat response 100-400 kHz). The pre-trigger time, duration discrimination time, and rearm time were set to $200 \mu \mathrm{s}, 400$ $\mu \mathrm{s}$, and $400 \mu \mathrm{s}$ respectively. The sampling rate was set to 5 $\mathrm{MHz}$ and the length of the stored signal was $819.2 \mu \mathrm{s}$.

\section{AE post-processing methods}

\section{SNR filtering}

As the major objective of this paper is to assign damage sources to the recorded AE signals, most reliable signals need to be kept for further analysis.

Although the settings for the pre-trigger time and stored length of the signal were determined by calibration with ultrasonic pulses and pencil lead breaks (PLB), it was found that these settings were not suitable to capture the onset of all occurring AE signals, e.g. when the signal had a low amplitude and a long rise-time, or when the first part of the signal was too noisy. For the signal analysis, it is favourable to analyse signals of which the waveform was completely stored. Therefore, AE signals were filtered based on their signal-to-noise ratio (SNR).

SNR gives the ratio of the signal power $S$ to the noise power $N . S$ is defined as the maximum absolute amplitude value in $\mathrm{mV}$ of the entire signal, whereas $N$ is defined as the maximum absolute amplitude value in $\mathrm{mV}$ of the first couple of microseconds of the signal. The SNR was calculated 
Table 3. Overview of the dummy samples.

\begin{tabular}{|c|c|c|}
\hline Name & Description & Possible AE sources \\
\hline Steel 1 & $\begin{array}{l}\text { Ribbed rebar in dry conditions }\left(20^{\circ} \mathrm{C}, 60 \% \mathrm{RH}\right) \text { (not } \\
\text { connected to a power supply) }\end{array}$ & Electromagnetic interference \\
\hline Steel 2 & $\begin{array}{l}\text { Ribbed rebar in a sodium chloride solution connected to } \\
\text { a power supply }\end{array}$ & Corrosion, electromagnetic interference \\
\hline Concrete 1 & Concrete prism in dry conditions $\left(20^{\circ} \mathrm{C}, 60 \% \mathrm{RH}\right)$ & Cement hydration, electromagnetic interference \\
\hline Concrete 2 & Concrete prism in a sodium chloride solution & $\begin{array}{l}\text { Cement hydration, absorption, electromagnetic } \\
\text { interference }\end{array}$ \\
\hline Beam 1 & Three-point bending test on an uncorroded $\mathrm{RC}$ beam & Concrete cracking \\
\hline
\end{tabular}

following equation (1). Based on the recorded AE signals, the SNR threshold was set to 10. If the SNR was larger than 10 , the difference between the actual signal and noise level was large enough and the signals were kept for further analysis.

The SNR criterion was found to be a reliable way to filter the AE signals. Moreover, it does not depend on the fixed threshold and can therefore be applied for other test setups as well. If the threshold was increased before acquisition, the same problem of missing the onset of certain signals would still occur. If the threshold was increased during post-processing, important low amplitude signals such as corrosion would have been missed.

$$
\mathrm{SNR}=20 \cdot \log _{10}\left(\frac{S}{N}\right)
$$

After filtering, AE events were localised in 1D. An event discrimination time of $2 \mathrm{~ms}$ was applied meaning that all hits belonging to the same event are recorded within this time frame. For the 2D setup (RC beams), 1D localization was performed with sensor pairs 1 and 2, 3 and 4, 1 and 3, and 2 and 4.

\section{AE parameter and signal analysis}

As a first step, cumulative AE event and AE energy curves were analysed. In a second step, the peak and centre frequency of localised AE events were investigated. The peak frequency of the signal was determined as the frequency with the maximum signal amplitude in the frequency domain. The centre frequency was determined as the centre of gravity of the signal in the frequency domain. In a third step, AE sources were distinguished and analysed in the time and frequency domain. Moreover, wavelet transforms (WT) were calculated to distinguish between $\mathrm{AE}$ events that show the same peak and centre frequency ranges.

The WT allows to analyse frequency components of an $\mathrm{AE}$ event as a function of time. It is a further extension of the short fourier transform (SFT) and overcomes the resolution problem of an $\mathrm{SFT}^{17}$. Instead of using a constant window shape as basis functions in case of an SFT, the basis functions are now small waves or wavelets that are scaled with respect to frequency.

The continuous WT is defined as ${ }^{12}$ :

$$
\operatorname{CWT}[a, b]=\int_{-\infty}^{\infty} \psi_{a, b}^{*} s(t) d t
$$

with

$$
\psi_{a, b}^{*}(t)=\frac{1}{\sqrt{a}} \psi\left(\frac{t-b}{a}\right)
$$

The parameter $a$ stretches or compresses the mother wavelet $\psi(t)$. The parameter $b$ shifts the wavelet over time. Several mother wavelets can be used. In this paper, the Morlet wavelet is used following previous research on corrosion in $\mathrm{RC}^{4}$. The basis function is as follows:

$$
\psi(t)=\exp \left(\frac{-t^{2}}{2}\right) \cos (5 t)
$$

Furthermore, average values of AE parameters such as amplitude, rise-time, and duration are discussed. The amplitude was defined as the maximum signal amplitude in the time domain, the rise-time was calculated as the time difference between the first threshold crossing and the moment the maximum amplitude is reached. The duration was calculated as the time difference between the first and last threshold crossing. The parameters are defined in ISO 12716-2001(E) and were obtained from the Vallen VisualAE software.

\section{Results of AE monitoring during rebar corrosion}

This section describes the general trends of the AE results over time obtained from monitoring the $\mathrm{RC}$ prisms and $\mathrm{RC}$ beams. AE source characterisation based on dummy samples and signal analysis will be discussed in the next section.

\section{Results of the RC prisms}

The cumulative localised AE events versus time of all samples is presented in figure 4. All results are shown against the average crack width which was measured every week.

When the sample does not show surface cracking during the corrosion process, the amount of AE events increases almost linearly as shown on the graphs of CL1-R1, CL1-S1, and CL2-S1. Possible AE sources are fluid flow of the sodium chloride solution through the (capillary) pore channels of concrete, further denoted as absorption, cement hydration, the corrosion process itself, and internal concrete micro-cracking. Uniform corrosion of steel not embedded in concrete is typically characterised by continuous signals whereas pitting corrosion is characterised by burst emissions ${ }^{18}$. AE events due to pitting corrosion are caused by the formation of salt crystals in the pits, hydrogen bubbles developed at the cathodic site, local plastic deformation of the pit, and the expansion of corrosion products ${ }^{18}$. The development of hydrogen bubbles at the cathodic site will not occur inside the RC sample as the cathode and anode are separated in the current corrosion setup. Besides, friction between the corrosion products and 

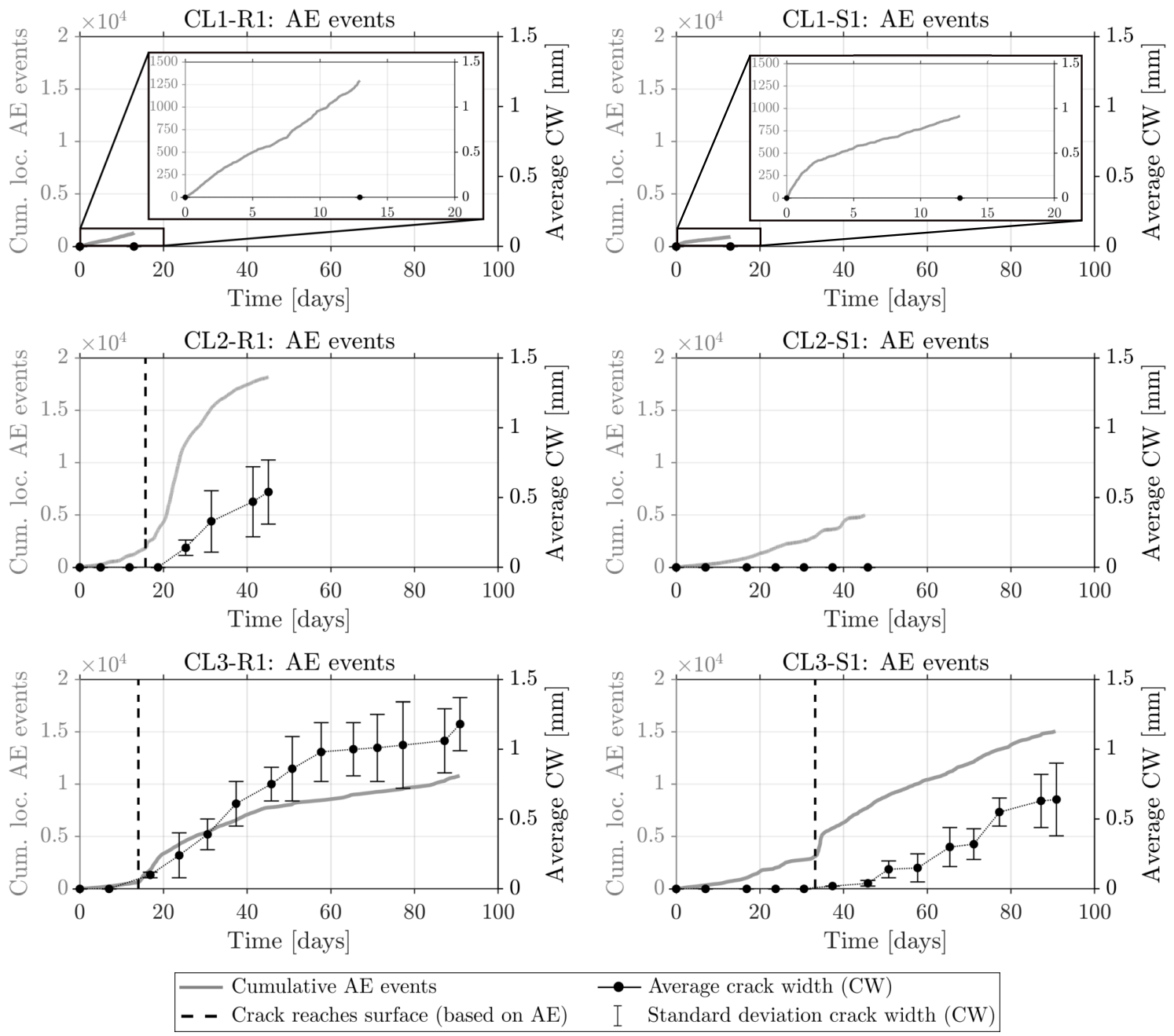

Figure 4. Average crack width (CW) and cumulative AE events versus time of samples with (left) ribbed rebar, and (right) smooth rebar.
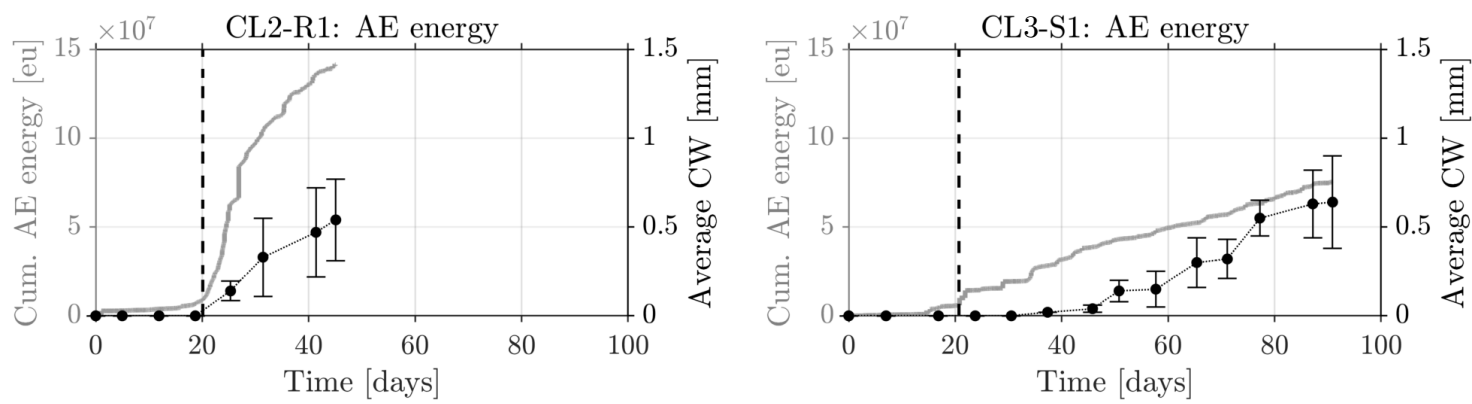

\begin{tabular}{|lll}
\hline - Cumulative AE energy & $\bullet-$ Average crack width $(\mathrm{CW})$ \\
- Crack reaches surface (based on AE) & I $\quad$ Standard deviation crack width $(\mathrm{CW})$ \\
\hline
\end{tabular}

Figure 5. Average crack width (CW) and cumulative AE energy versus time of samples (left) CL2-R1, and (right) CL3-S1.

the concrete matrix due to movement of these corrosion products in pores and cracks, and debonding (loss of adhesion between steel and concrete) may occur.

The moment that the crack reaches the surface was distinguished by the first significant increase of the cumulative $\mathrm{AE}$ events and is indicated on figure 4 by the dashed line. This was evidenced by comparing the cumulative $\mathrm{AE}$ curves with the crack width measurements. However for sample CL2-R1, this increase occurs on day 15 when no crack was observed during the next crack width measurements.
For all samples, also the cumulative amount of AE energy was analysed. The AE energy is calculated by squaring and integrating the AE signal. The energy unit (eu) is equal to $10^{-14} \mathrm{~V}^{2} \mathrm{~s}$. Values were imported in Matlab from the Vallen VisualAE software. It is found that the moment of cracking can also be observed by an increase in cumulative AE energy. In case of sample CL2-R1 (figure 5 (left)), the increase of the cumulative is in line with the crack measurements. However, it was found that for sample CL3-S1 (figure 5 (right)), the cumulative AE energy increases from day 20 which is earlier than the increase of the AE events. 

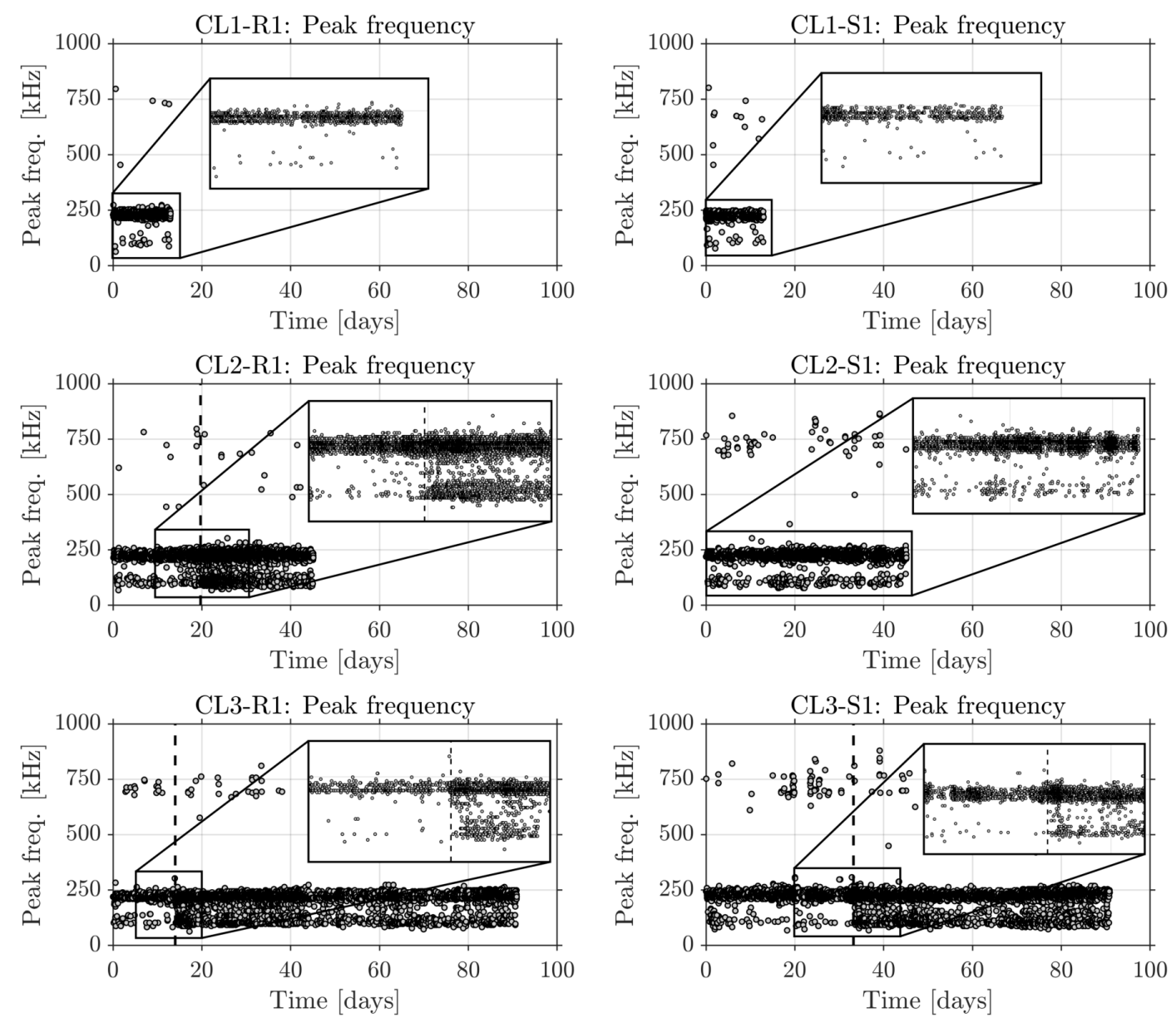

Figure 6. Peak frequency versus time of samples with (left) ribbed rebar, and (right) smooth rebar.
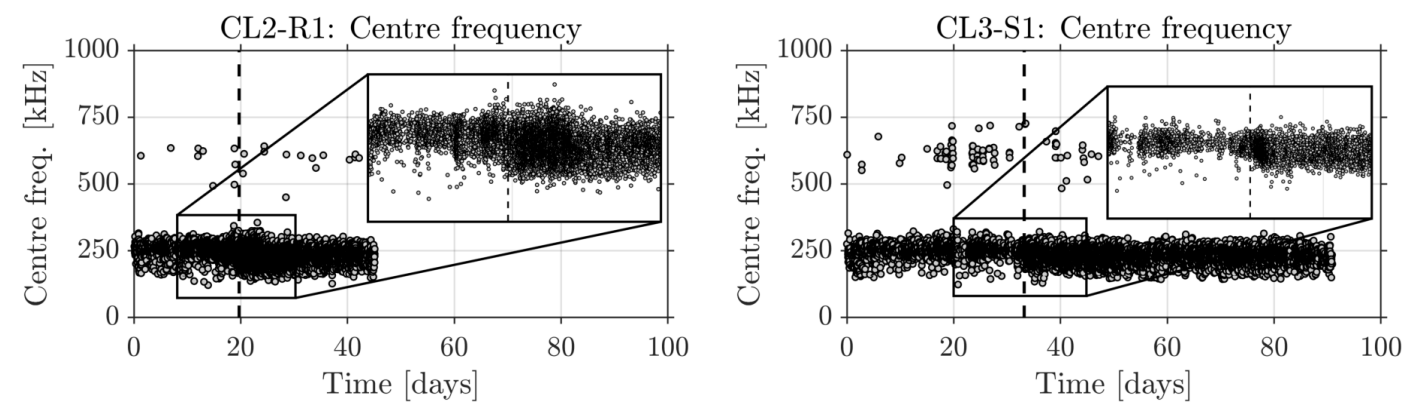

Figure 7. Centre frequency versus time for (left) sample CL2-R1, and (right) CL3-S1.

For most samples, the increase in $\mathrm{AE}$ events and $\mathrm{AE}$ energy was observed on the same day. For samples CL2-R1 and CL3-S1, the increase was noticed on a different day. The approach can therefore not be generalised for all samples. Moreover, note that the entire history is needed to pinpoint the moment of cracking as the increase of $\mathrm{AE}$ events and AE energy is different for each sample. Validation with crack measurements is required, making this approach less suitable for on-site application.

In a next step, the peak and centre frequency of the AE signals was investigated. Figure 6 shows the peak frequencies of all samples. A shift towards lower frequencies can be seen as soon as the surface crack starts to grow. The moment of macro-crack formation was determined from the previously described analysis of the cumulative $\mathrm{AE}$ energy/events compared with the crack width measurements (figure 4), and is indicated by the dashed line. For example for sample CL3-R1, the average peak frequency before cracking is $228 \mathrm{kHz}$ (SD $85 \mathrm{kHz}$ ). After crack initiation, the average peak frequency decreases to $210 \mathrm{kHz}$ (SD $48 \mathrm{kHz}$ ).

For samples CL2-R1 and CL3-S1, the moment of cracking was more difficult to determine based on the cumulative amount of AE events and AE energy. However for both samples, the shift in peak frequency is clear and in line with the observations of the crack measurements.

As observed from figure 4, the AE events of sample CL2R1 increased at day 15 whereas the increase in AE energy was at day 20. It was observed that the few lower frequent signals between day 15 and 20 were recorded. This may indicate that the sample was already severely cracking inside before the crack reached the surface, however, this could not be validated by other measurements. The same holds 
for sample CL3-S1 where the increase in AE events was on day 35 , but on day 20 when looking at the AE energy. Here, few lower frequent signals with a high energy were observed before day 20.

For samples CL3-R1, CL1-S1, CL2-S1, and CL3-S1 also a group of events having a higher frequency (above $400 \mathrm{kHz}$ ) was observed. Possible AE sources will be assigned in the next section.

The same analysis was performed for the centre frequency. The results of samples CL2-R1 and CL3-S1 are shown in figure 7. The shift is visually less pronounced than for the peak frequency, however, also a decrease can be noticed. For example for sample CL2-R1 the average centre frequency before cracking is $250 \mathrm{kHz}$ (SD $29 \mathrm{kHz}$ ). The centre frequency decreases to $230 \mathrm{kHz}$ (SD $29 \mathrm{kHz}$ ) after cracking.

\section{Results of the RC beams}

Similar results were found for the RC beams. Figures 8 and 9 show the cumulative AE events and AE energy of signals that were localised in 1D for samples B10R1 and B10R2 respectively. The moment the crack reaches the surface and continues to grow causes an increase of both AE event and energy rate. This is indicated by the dashed line and is evidenced by crack measurements.

As was the case for the RC prisms, the moment the crack reaches the surface can be distinguished based on the frequency content of the signals, although the shift is less pronounced. The peak and centre frequency of each event versus time of sample B10R1 are shown in figure 10. Figure 11 shows the same for sample B10R2. Notice that there is a decrease of both peak and centre frequency when the surface crack starts to grow. Due to a malfunction of the AE system, waveforms were not stored for four days in case of beam B10R2. This is indicated by the grey area in figure 11 . The $\mathrm{AE}$ parameters such as AE energy were still stored and were imported in Matlab to obtain the cumulative AE events and AE energy curves shown in figure 9.

It can be concluded from this section that the onset of macro-cracking can be distinguished from the cumulative $\mathrm{AE}$ events and AE energy. However, the increase is sample dependent and crack measurements are favourable. Before macro-cracking, the cumulative AE curves increase linearly. The onset of concrete macro-cracking can be distinguished by an increase of the $\mathrm{AE}$ activity. After macro-crack initiation, the cumulative AE curves follow the same trend as the crack width. The shift in peak and centre frequency tend to be a better indicator. Ongoing AE sources will be studied more in depth in the next section.
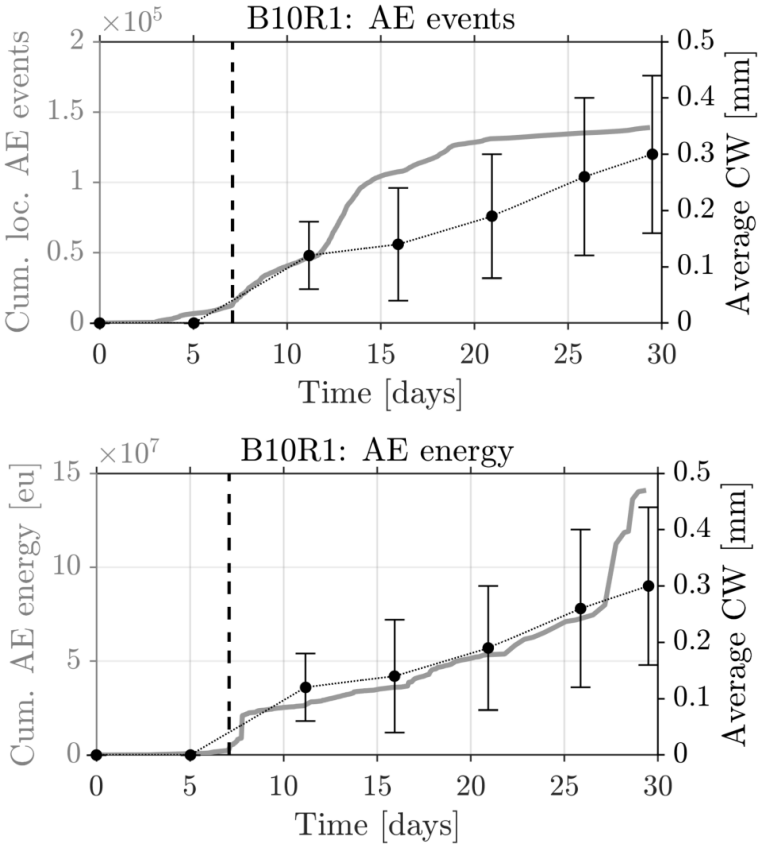

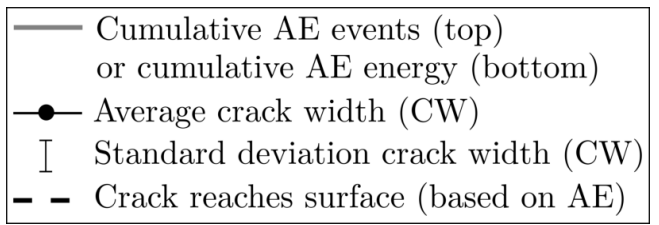

Figure 8. Average crack width (CW) and cumulative $A E$ events versus time (top) and average crack width (CW) and cumulative $A E$ energy versus time (bottom) of beam B10R1.
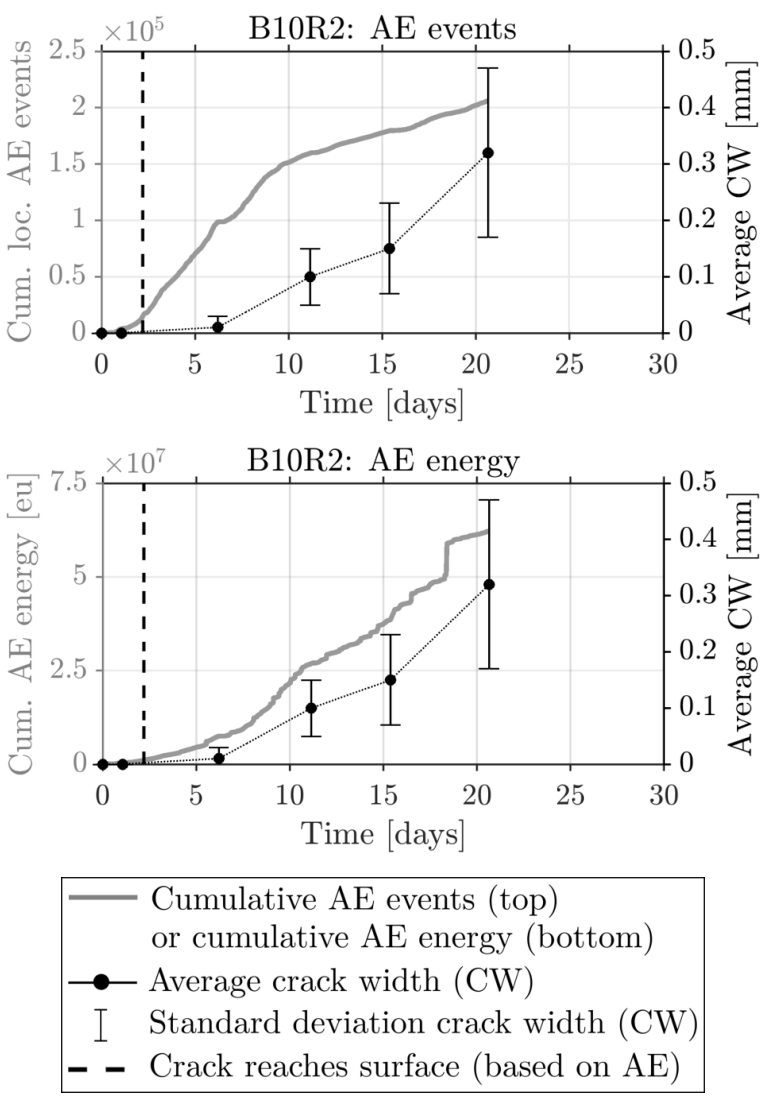

Figure 9. Average crack width (CW) and cumulative $A E$ events versus time (top) and average crack width (CW) and cumulative $A E$ energy versus time (bottom) of beam B10R2. 

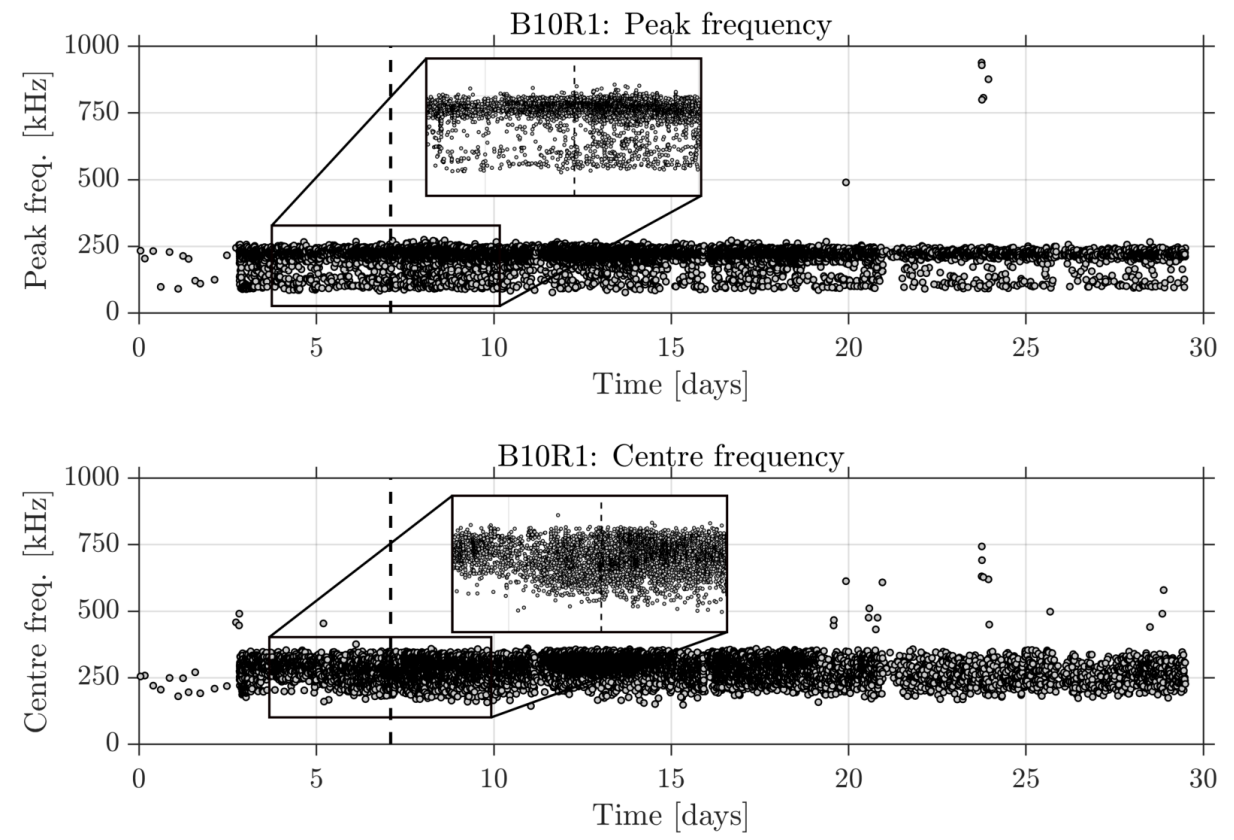

Figure 10. Sample B10R1: (top) peak frequency versus time, and (bottom) centre frequency versus time.
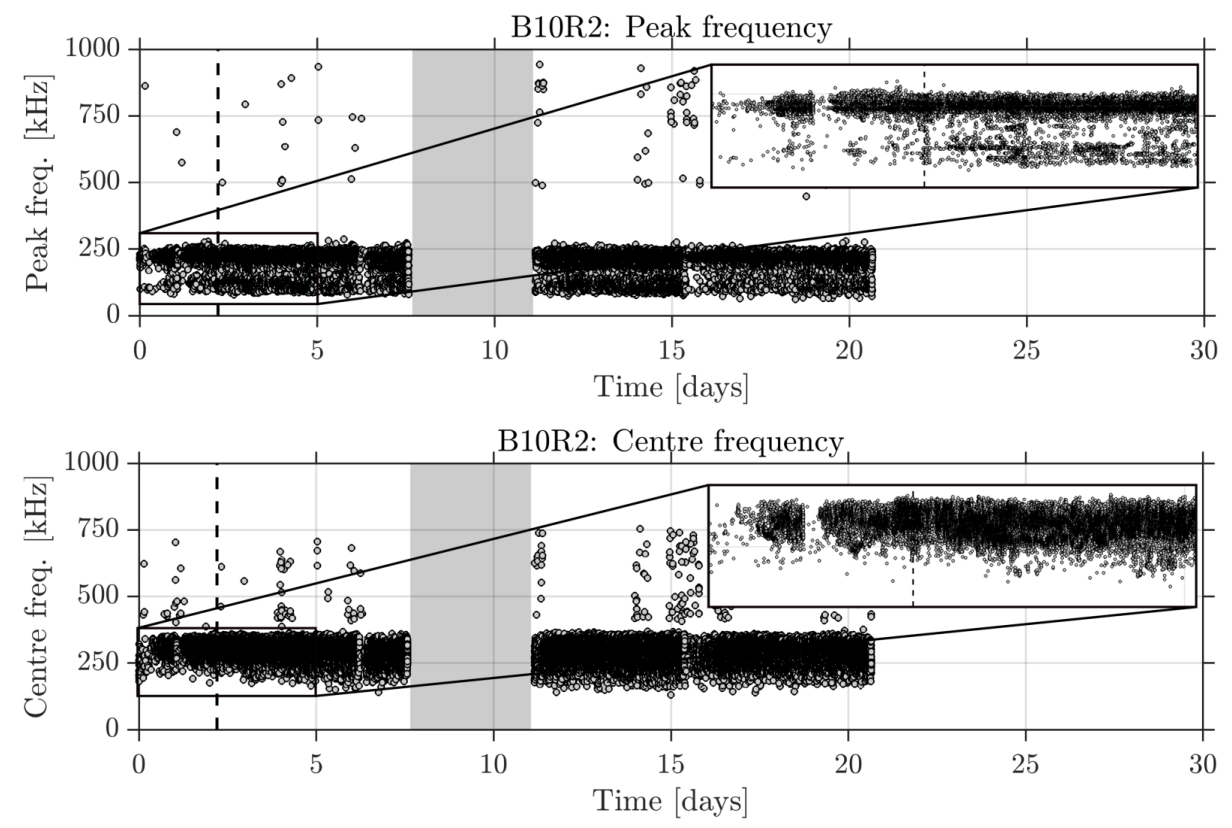

Figure 11. Sample B10R2: (top) peak frequency versus time, and (bottom) centre frequency versus time; the area in grey indicates a lack of $A E$ data due to malfunction of the $A E$ system.

\section{AE source characterisation}

In this section, AE sources will be characterised by comparing the signals obtained in the accelerated corrosion tests and in the dummy samples. The signals will be compared in the time and frequency domain. Also the contour map of the wavelet transform (WT) will be analysed.

As previously presented in table 3 a set of dummy samples in which specific AE sources were isolated, was tested. The dummy samples are divided in three groups: (1) tests on rebars only, (2) tests on concrete prisms, and (3) a three-point bending test on an uncorroded RC beam.

Results of the first group (steel) are shown in figure 12 . Based on sample Steel 1, electromagnetic interference can be distinguished. These signals have a peak frequency which is higher than $450 \mathrm{kHz}$. Their centre frequency is higher than $375 \mathrm{kHz}$. The signals could easily be recognised by their apparent source location. As these signals are caused by electrical interference on the AE system (e.g. by switching the light on and off), the signal reaches both sensors at the same time. As the arrival time is the same for both sensors, these signals are localised in the middle of the two sensors. Moreover, it was found that these signals occurred at the same time in samples Steel 1 and Steel 2. A typical signal in the time and frequency domain as well as the contour map of the WT is shown in figure 13. The signals are characterised by a short rise-time (average (AVG) 15 $\mu \mathrm{sec}, \mathrm{SD} 31 \mu \mathrm{sec}$ ) and a short duration (AVG $83 \mu \mathrm{sec}$, SD $127 \mu \mathrm{sec})$. The average amplitude of the signals is found to 

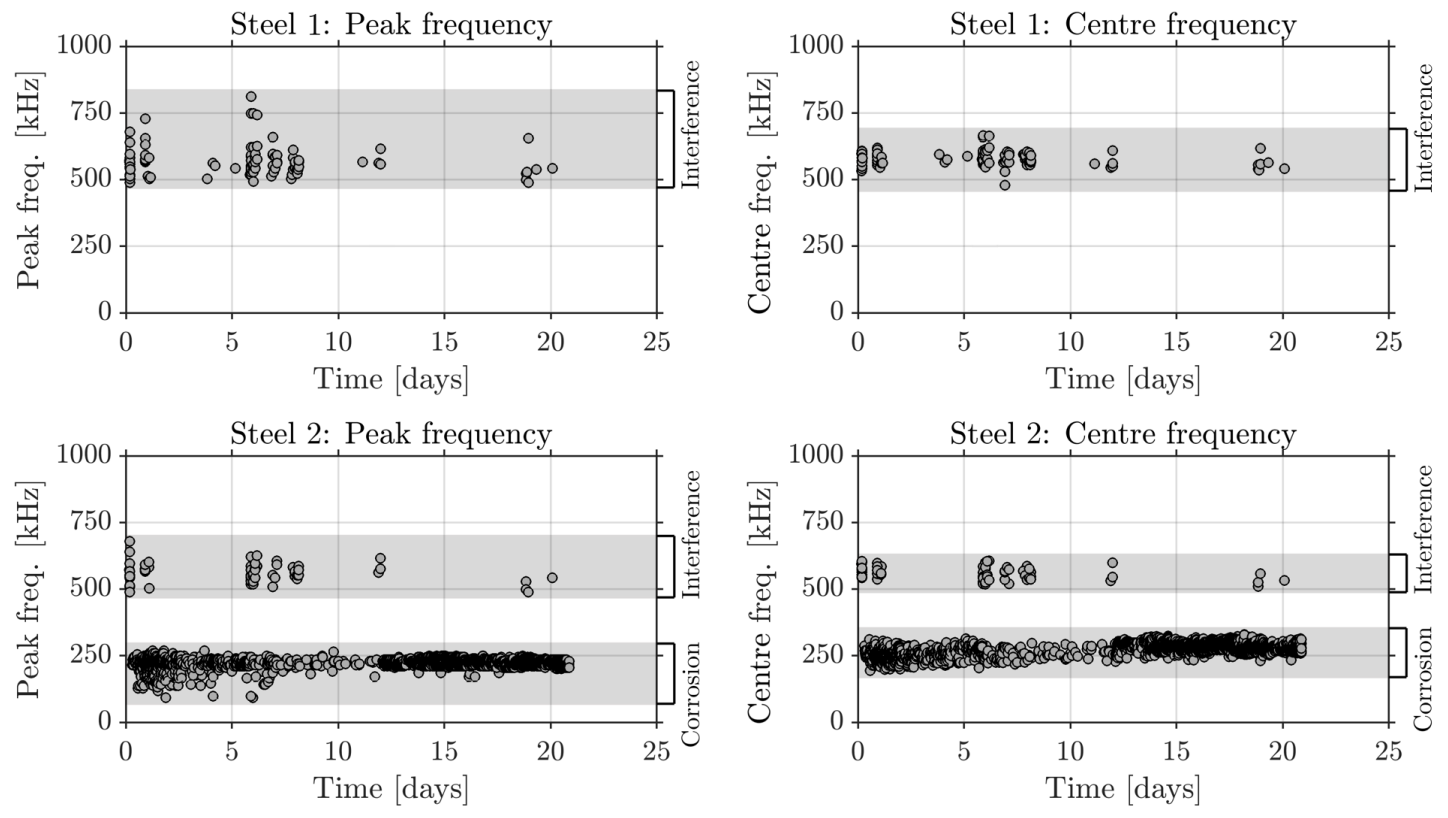

Figure 12. Peak frequencies (left) and centre frequencies (right) of the AE signals captured on rebars not embedded in concrete.
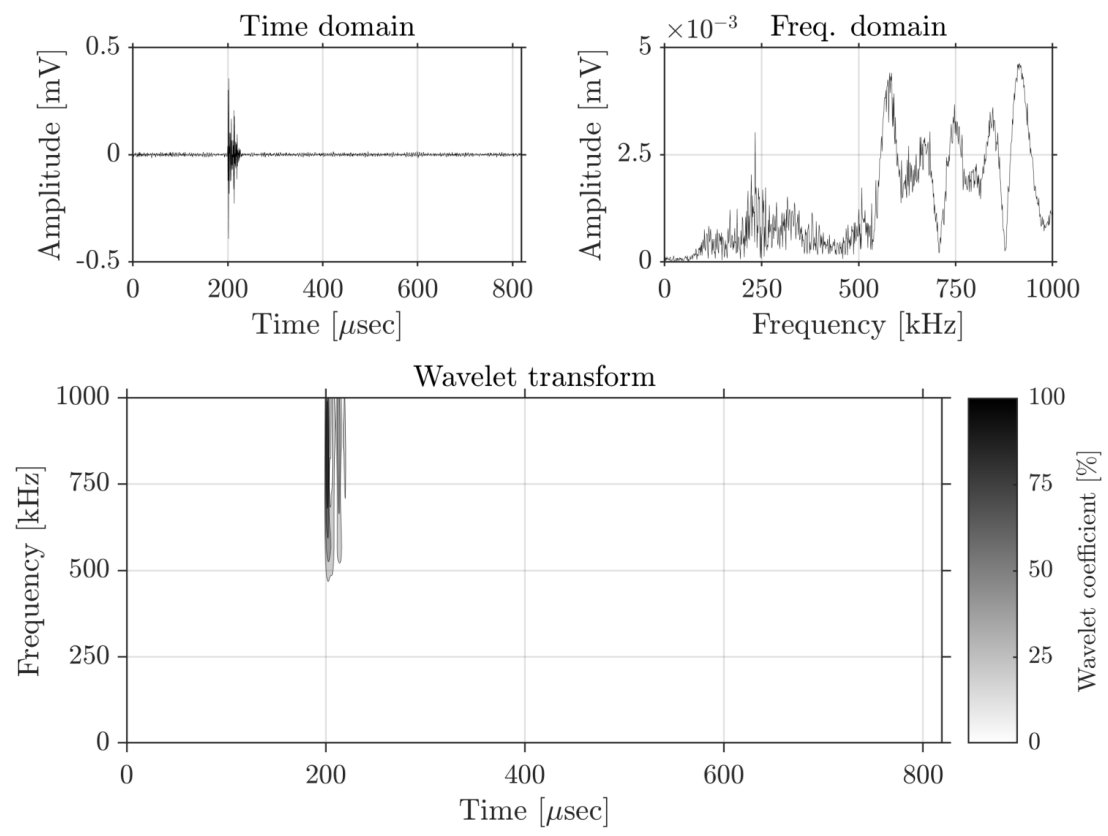

Figure 13. Typical signal due to electromagnetic interference in the time (top left) and frequency (top right) domain, and contour map of the wavelet transform (bottom).

be $47 \mathrm{~dB}(\mathrm{SD} 5 \mathrm{~dB})$. The contour map of the WT shows a very localised signal in time, ranging between 500 and $1000 \mathrm{kHz}$. In the corrosion tests, also signals with a peak frequency around $220 \mathrm{kHz}$ were found to be originating from electromagnetic interference. They can be distinguished based on the presence of high frequency components and the shape of the WT.

Sample Steel 2 can corrode as it is immersed in a sodium chloride solution and connected to a power supply. Based on the peak and centre frequencies of the signals, this sample shows a second group with a peak frequency around $220 \mathrm{kHz}$ which can be assigned to the corrosion process. Few signals with a lower peak frequency (below $200 \mathrm{kHz}$ ) were also observed in the beginning. The average centre frequency is $292 \mathrm{kHz}$ (SD $23 \mathrm{kHz}$ ). A typical signal is shown in figure 14.
The signals are characterised by low amplitudes (AVG 45 $\mathrm{dB}, \mathrm{SD} 5 \mathrm{~dB}$ ) and have a long duration (AVG $227 \mu \mathrm{sec}, \mathrm{SD}$ $220 \mu \mathrm{sec}$ ). The average rise-time is $38 \mu \mathrm{sec}$ (SD $62 \mu \mathrm{sec}$ ). Based on the contour map of the WT, a slowly damping signal can be seen leading to a long duration.

Sample Steel 2 gives typical signals from the corrosion process of a rebar not embedded in concrete. Therefore, a typical signal of corrosion of steel in concrete obtained in the initial phase of the accelerated corrosion tests on the beams was analysed subsequently and is shown in figure 15. It was found that the corrosion process could be captured when the rebar was embedded in the concrete. The signals were found to have an amplitude below $50 \mathrm{~dB}$. These signals were only observed during the accelerated corrosion tests and not in the dummy samples which strengthens the finding that 

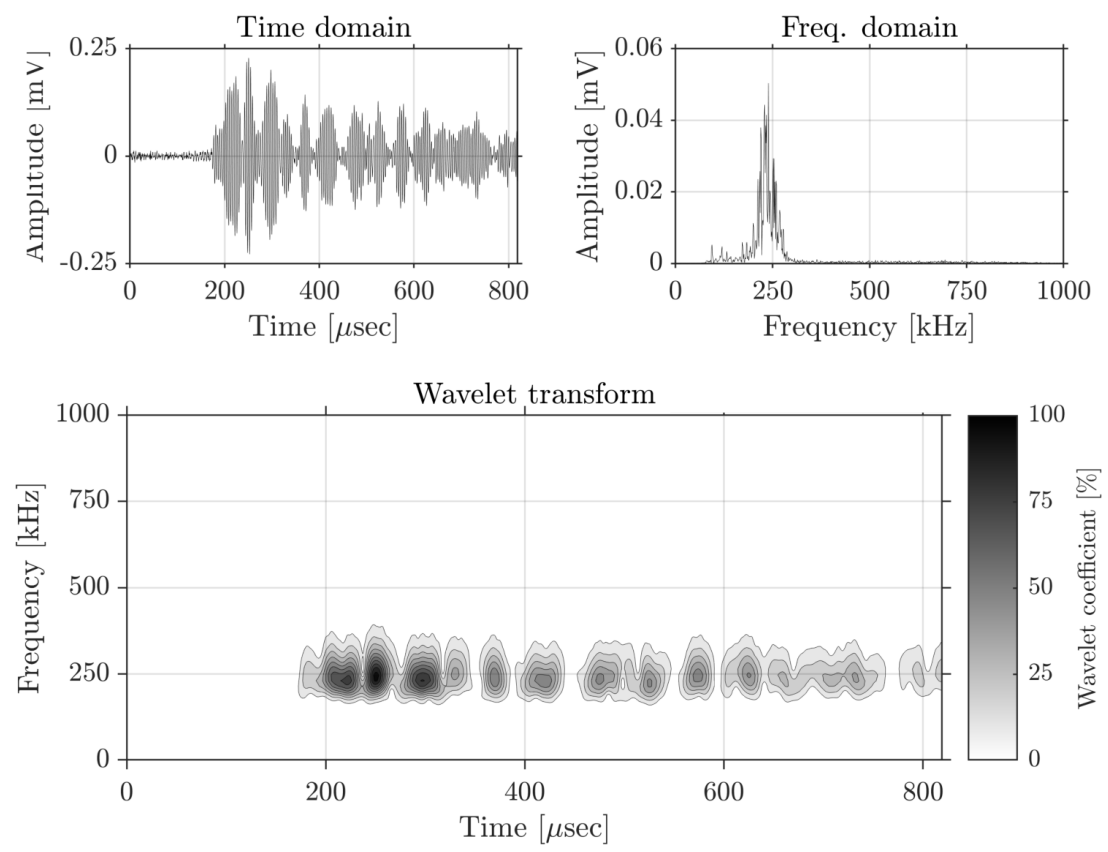

Figure 14. Typical signal of corrosion in steel not embedded in concrete in the time (top left) and frequency (top right) domain, and contour map of the wavelet transform (bottom).
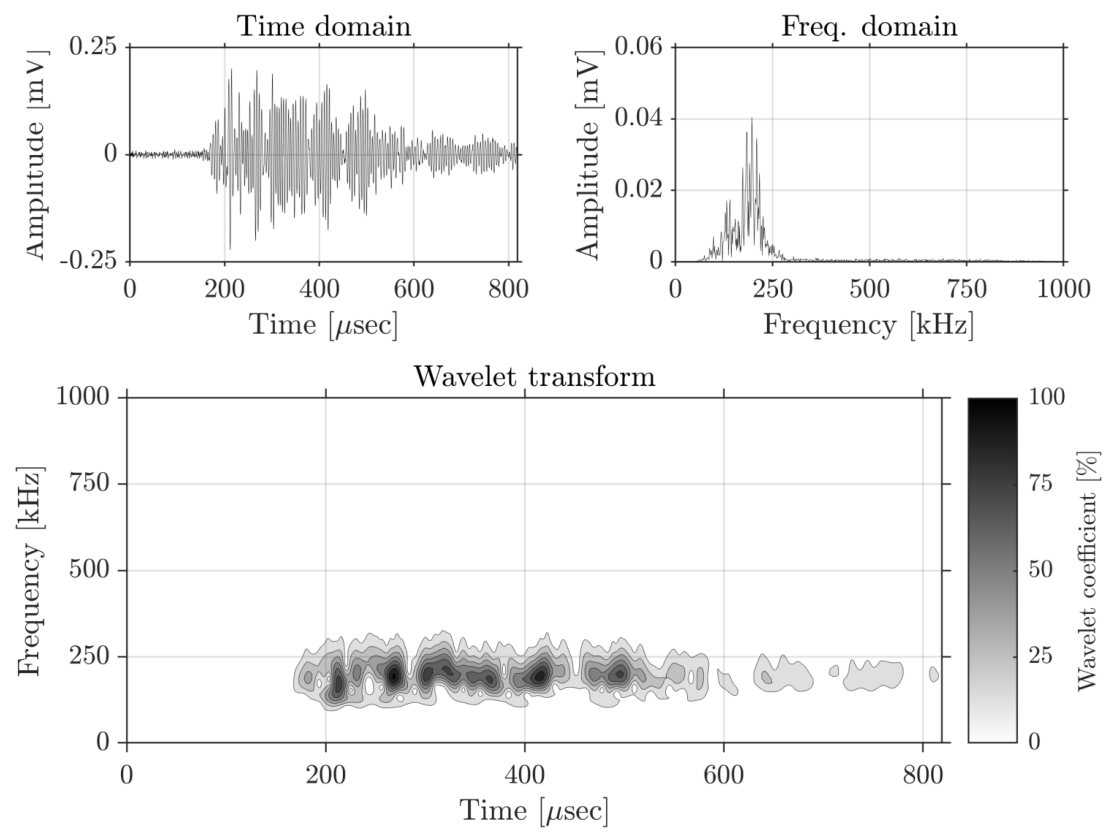

Figure 15. Typical signal of corrosion in steel embedded in concrete in the time (top left) and frequency (top right) domain, and contour map of the wavelet transform (bottom).

these signals are caused by the corrosion process itself. The contour map of the WT shows a signal with a slow damping and therefore a long duration. The signal is slightly altered due to a different travel path.

Results of the second group (concrete prisms) are shown in figure 16. These dummy samples were used to distinguish cement hydration and absorption of the sodium chloride solution. The samples did not contain a rebar.

Concrete 1 is a concrete prism that was taken from the curing room $\left(20 \pm 1^{\circ} \mathrm{C}, 95 \pm 3 \% \mathrm{RH}\right)$ and placed in the climatised room $\left(20 \pm 1^{\circ} \mathrm{C}, 60 \pm 3 \% \mathrm{RH}\right)$ at the same age as the RC beams (29 days). The sample was placed in dry conditions. Based on this sample, signals due to cement hydration can be distinguished. It was found that this process mainly occurs in the beginning of the test and decreases over time. The peak frequency is around $220 \mathrm{kHz}$ and the centre frequency around $270 \mathrm{kHz}$. Figure 17 shows a typical signal. The signals are characterised by a low average amplitude of $49 \mathrm{~dB}$ (SD $7 \mathrm{~dB}$ ), an average duration of $89 \mu \mathrm{sec}$ (SD $91 \mu \mathrm{sec}$ ), and an average rise-time of $13 \mu \mathrm{sec}$ (SD 18 $\mu \mathrm{sec})$. The contour map of the WT shows that the signal is mainly localised in the first $30 \mu \mathrm{sec}$. The signals are quickly damping and have a short duration. 

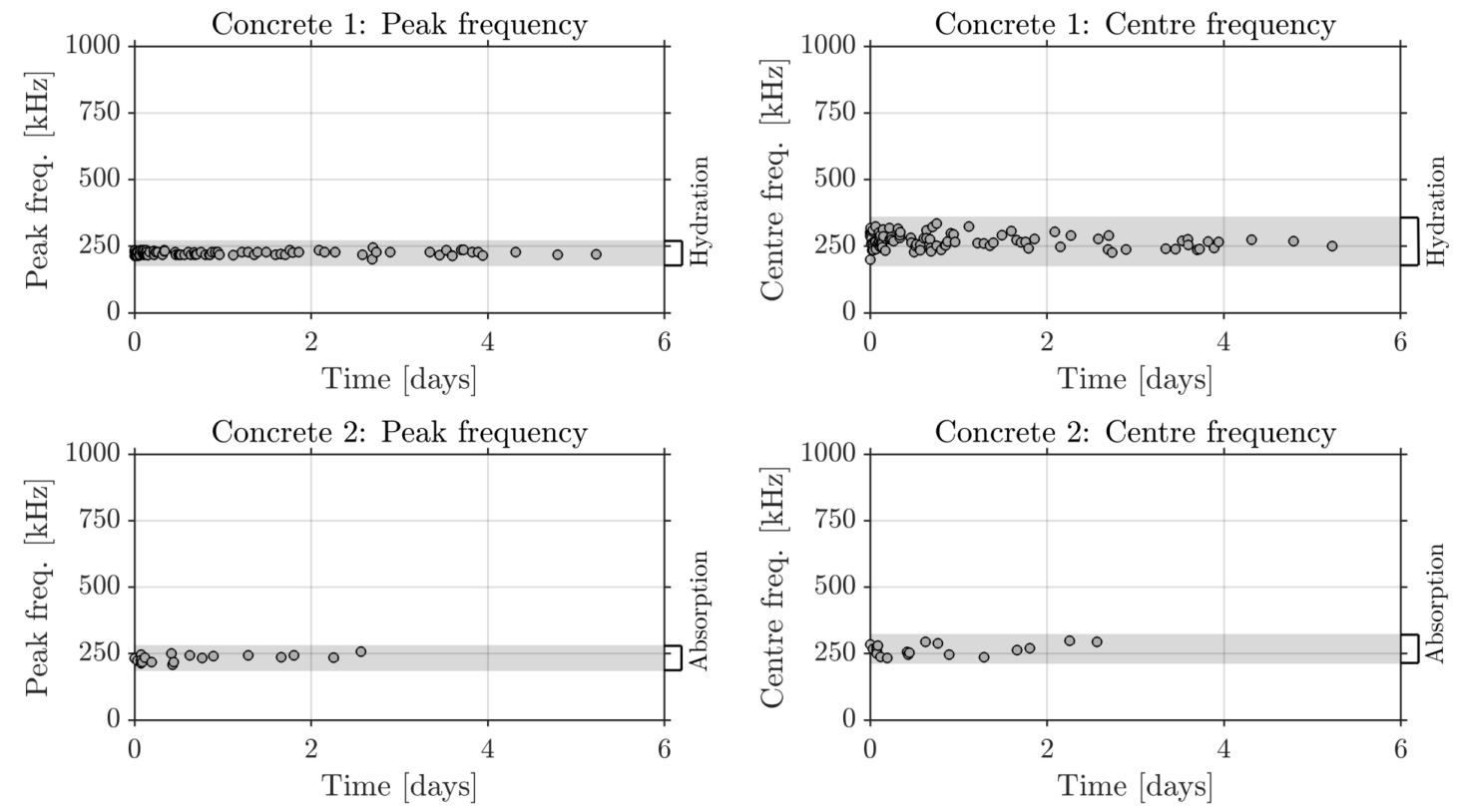

Figure 16. Peak frequencies (left) and centre frequencies (right) of the AE signals captured on concrete samples.
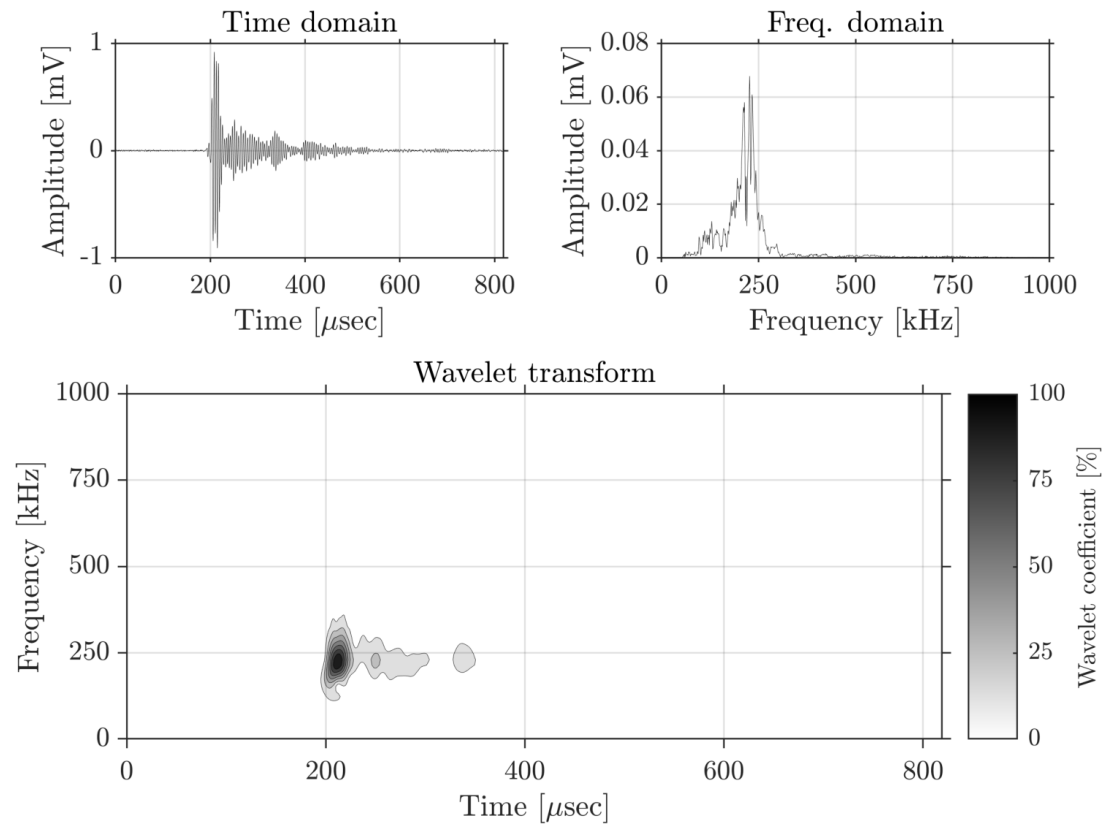

Figure 17. Typical signal of cement hydration in the time (top left) and frequency (top right) domain, and contour map of the wavelet transform (bottom).

Signals due to absorption, can be distinguished in sample Concrete 2. This concrete prism had aged in the climatised room for more than two years. Therefore, cement hydration was less likely to occur and the main AE source was expected to be absorption of the sodium chloride solution. AE hits caused by absorption of the electrolyte were also reported by Goldaran et al. ${ }^{19}$ and Zheng et al. ${ }^{11}$. The concrete prism was completely dry and placed in a sodium chloride solution. As was the case for cement hydration, this process mainly occurs in the beginning of the test. Once the concrete is saturated, AE events are not recorded anymore. The peak and centre frequency of the signals are respectively around 230 and $265 \mathrm{kHz}$. A typical signal is shown in figure 18. The average amplitude was found to be $46 \mathrm{~dB}$ (SD $5 \mathrm{~dB}$ ). The average duration and rise-time were respectively $156 \mu \mathrm{sec}$
(SD $129 \mu \mathrm{sec}$ ) and $32 \mu \mathrm{sec}$ (SD $29 \mu \mathrm{sec}$ ). The representation of the signal in the frequency domain and the contour map of the WT show an important share of lower frequencies.

Electrical interference was recorded for samples Concrete 1 and 2, however, these signals were not localised and are therefore not shown in figure 16. As seen in figures $6,7,10$, and 11, electromagnetic interference was also measured during the accelerated corrosion tests on the RC prisms and beams. As discussed before, these signals can be distinguished by high peak and centre frequencies. In general, it was found that electromagnetic interference was more likely to be recorded on samples containing a rebar than in plain concrete. 

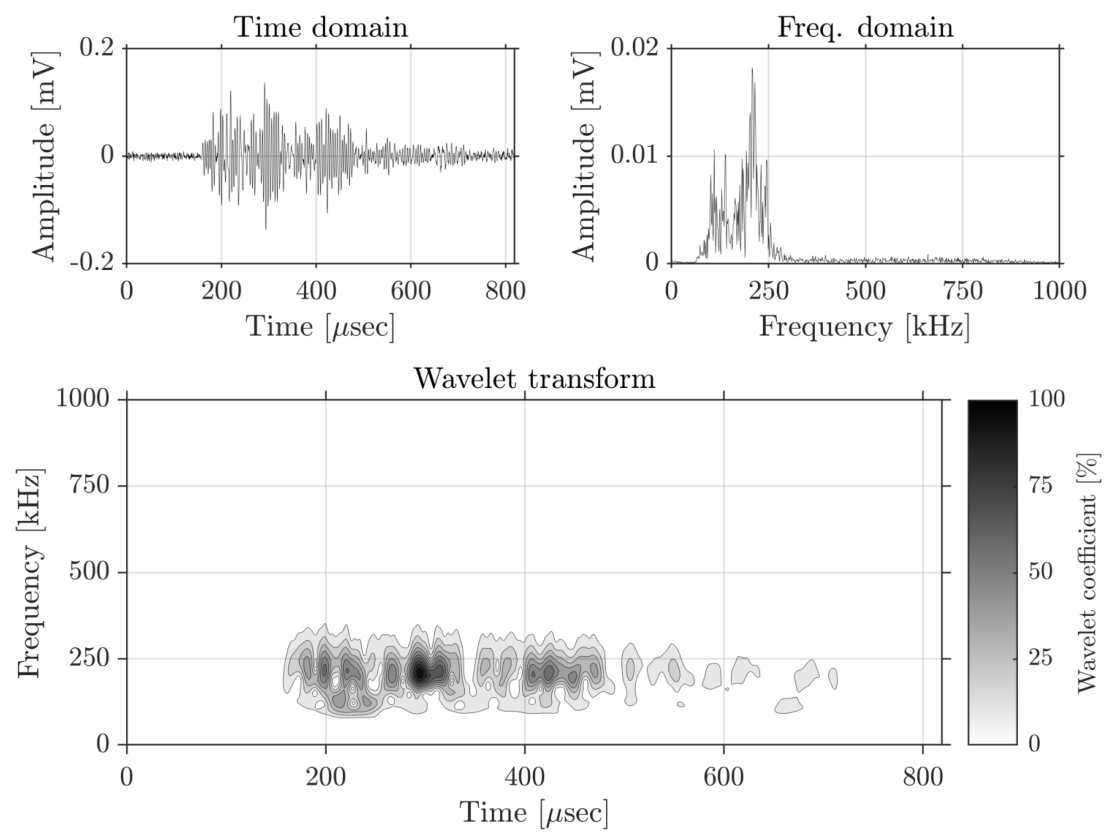

Figure 18. Typical signal of absorption in the time (top left) and frequency (top right) domain, and contour map of the wavelet transform (bottom).
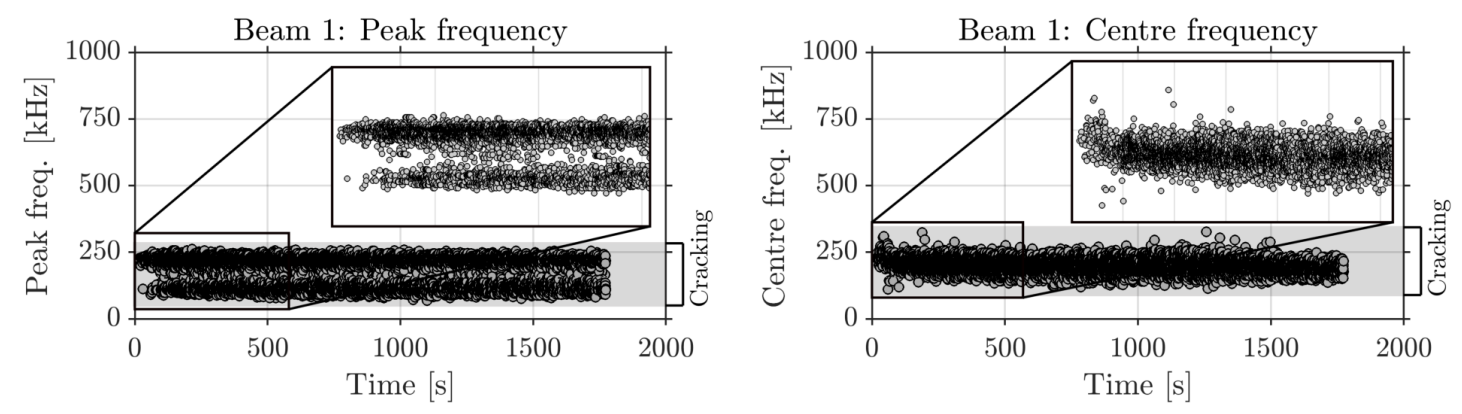

Figure 19. AE signals captured during a three-point bending test of an uncorroded RC beam, (left) peak frequencies, and (right) centre frequencies.

To investigate typical signals from concrete cracking, the signals of an uncorroded RC beam subjected to a threepoint bending test were compared. The result is shown in figure 19. Three signal groups can be distinguished, the first group having a peak frequency around $220 \mathrm{kHz}$, the second group having a peak frequency around $220 \mathrm{kHz}$ and a smaller peak around $100 \mathrm{kHz}$, and the third group having a peak frequency around $100 \mathrm{kHz}$. The first group mainly occurs in the beginning of the test, the second group throughout the entire test, and the third mainly after occurrence of bending cracks.

A first group consists of signals having a clear peak around $220 \mathrm{kHz}$ (figure 20). Some of these signals also show a small peak above $250 \mathrm{kHz}$. The average amplitude of these signals is $50 \mathrm{~dB}(\mathrm{SD} 8 \mathrm{~dB})$. The average rise-time was found to be $25 \mu \mathrm{sec}$ (SD $30 \mu \mathrm{sec}$ ), and the average duration $152 \mu \mathrm{sec}$ (SD $146 \mu \mathrm{sec}$ ). The WT shows a localised signal during the first $200 \mu \mathrm{sec}$. It was found that it can be difficult to distinguish between corrosion of steel in concrete and these signals originating from concrete cracking. However when comparing figures 15 and 20, the signals from cracking show a shorter duration with large WT coefficients in the first 400 $\mu \mathrm{sec}$ whereas signals from corrosion show a longer duration with large WT coefficients in the first $600 \mu \mathrm{sec}$.
A second group contains signals with a peak frequency around $220 \mathrm{kHz}$ and a second peak around $100 \mathrm{kHz}$ (figure 21). The signals belonging to this group have an average amplitude of $53 \mathrm{~dB}$ (SD $8 \mathrm{~dB}$ ), an average rise-time of 40 $\mu \mathrm{sec}$ (SD $30 \mu \mathrm{sec}$ ), and an average duration of $263 \mu \mathrm{sec}$ (SD $183 \mu \mathrm{sec}$ ). As was the case for group 1, the highest wavelet coefficients are found in the first $200 \mu \mathrm{sec}$ of the signal. The difference with group 1 is the presence of lower frequencies. Note that the signals can be similar to the signals originating from absorption. However, it can be expected that signals due to absorption are mainly occurring the beginning of the test, whereas cracking starts after corrosion initiation.

A third group consists of signals having a peak frequency around $100 \mathrm{kHz}$. A typical signal is shown in figure 22. These signals have a higher average amplitude of $56 \mathrm{~dB}$ (SD 11 $\mathrm{dB}$ ), a higher average rise-time of $49 \mu \mathrm{sec}$ (SD $38 \mu \mathrm{sec}$ ), and a higher average duration of $389 \mu \mathrm{sec}$ (SD $214 \mu \mathrm{sec}$ ) than groups 1 and 2 . The highest wavelet coefficients are found in the first $400 \mu \mathrm{sec}$ of the signal. The signals can easily be distinguished by their low frequency components.

Table 4 shows an overview and summary of all possible AE sources with their most important characteristics. A distinction of the AE sources only based on AE parameters such as amplitude, rise-time and duration proves difficult. 

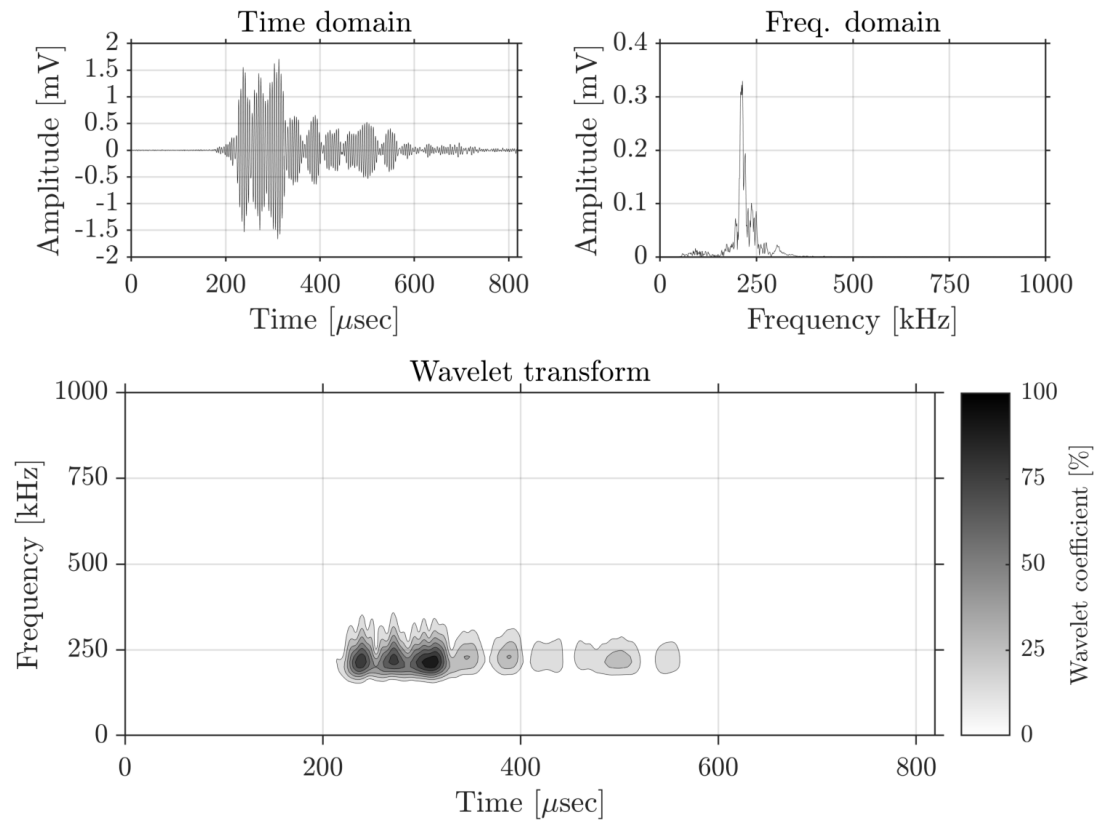

Figure 20. Typical signal of concrete cracking (group 1) in the time (top left) and frequency (top right) domain, and contour map of the wavelet transform (bottom).
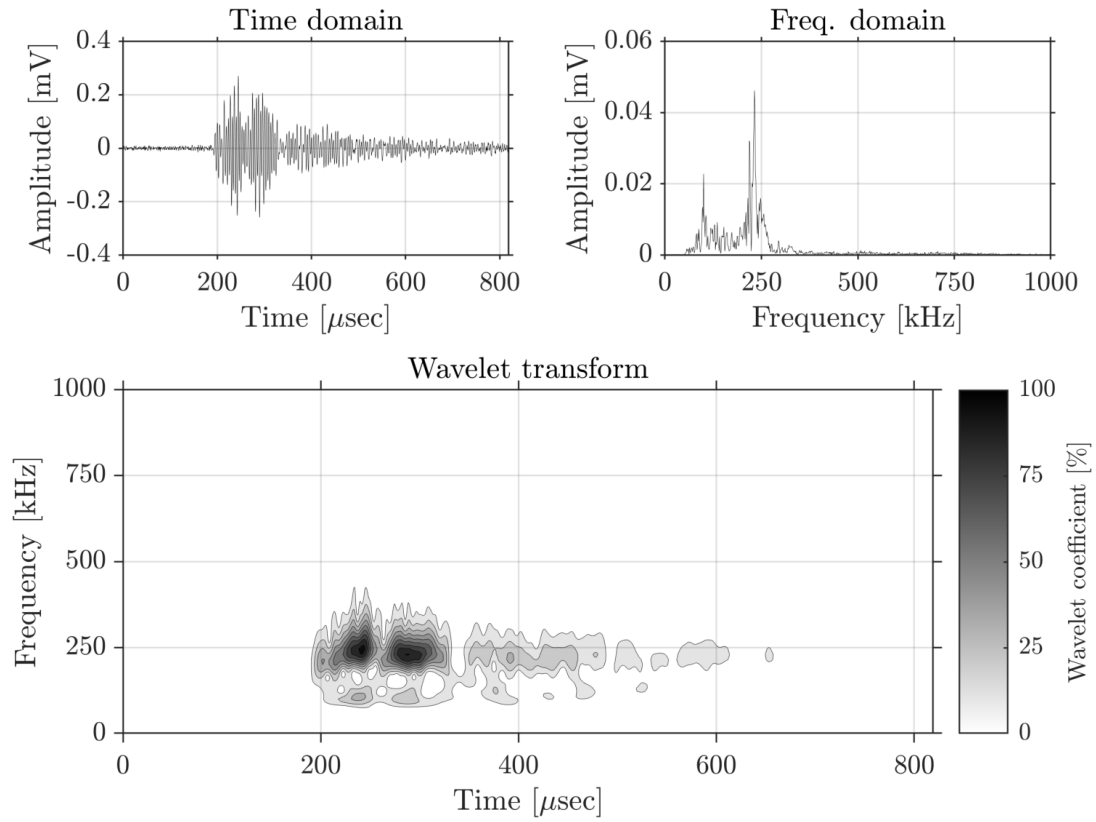

Figure 21. Typical signal of concrete cracking (group 2) in the time (top left) and frequency (top right) domain, and contour map of the wavelet transform (bottom).

Amplitude ranges overlap and parameters such as rise-time and duration depend on the pre-defined threshold. Therefore, for low amplitude signals, the duration and rise-time can be equal to zero. In general, large differences between minimum and maximum values can be noticed for the amplitude, duration, and rise-time.

To characterise the sources, signal analysis can help However, except for signals originating from electromagnetic interference, the peak and centre frequency ranges of the different AE sources overlap. This may be caused by the sensor sensitivity and its effect on the signal transfer function. Although broadband sensors with a flat frequency response were chosen, the applied sensors are most sensitive around $220 \mathrm{kHz}$. Therefore, most signals may show a peak in the frequency domain around $220 \mathrm{kHz}$. In order to make a better distinction, the contour maps of the WTs are shown in the discussion. Still, it is found that signals originating from corrosion, absorption, and micro-concrete cracking (group 12) were difficult to distinguish from each other. In that case, the moment of occurrence during the test can help.

These results validate the initial observations made in the previous section. Signals occurring in the beginning of the test such as absorption, cement hydration, and microcracking (group 1-2) are characterised by a higher frequency around $220 \mathrm{kHz}$. The decrease in frequencies can now be attributed to the occurrence of concrete cracking, especially macro-cracking with low amplitude (group 3). 

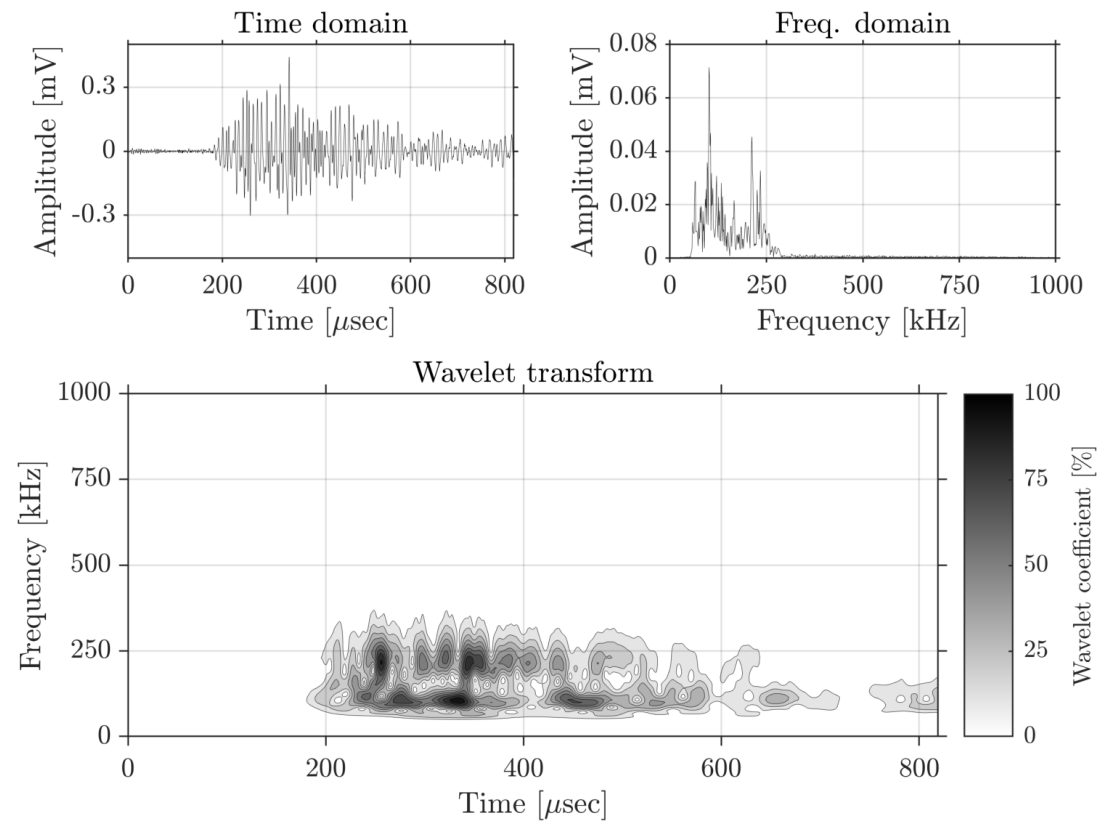

Figure 22. Typical signal of concrete cracking (group 3) in the time (top left) and frequency (top right) domain, and contour map of the wavelet transform (bottom).

Table 4. Overview of different $A E$ sources and their most important characteristics.

\begin{tabular}{llllll}
\hline AE source & $\begin{array}{l}\text { Amplitude }[\mathrm{dB}] \\
\text { Average }(\text { range) }\end{array}$ & $\begin{array}{l}\text { Rise-Time }[\mu \mathrm{sec}] \\
\text { Average }(\text { range) }\end{array}$ & $\begin{array}{l}\text { Duration }[\mu \mathrm{sec}] \\
\text { Average }(\mathrm{range})\end{array}$ & $\begin{array}{l}\text { Peak freq. }[\mathrm{kHz}] \\
\text { Average (range) }\end{array}$ & $\begin{array}{l}\text { Centre freq. }[\mathrm{kHz}] \\
\text { Average }(\mathrm{range})\end{array}$ \\
\hline Corrosion & $45(40-70)$ & $38(0-590)$ & $227(0-640)$ & $220(100-280)$ & $292(190-360)$ \\
Cement hydration & $49(40-80)$ & $13(0-100)$ & $89(0-410)$ & $223(200-240)$ & $270(200-340)$ \\
Absorption & $46(40-60)$ & $32(0-100)$ & $156(0-370)$ & $232(210-260)$ & $265(230-300)$ \\
Concrete cracking group 1 & $50(40-80)$ & $25(0-210)$ & $152(0-640)$ & $221(200-250)$ & $272(210-340)$ \\
Concrete cracking group 2 & $53(40-80)$ & $40(0-170)$ & $263(0-630)$ & $219(180-250)$ & $233(170-290)$ \\
Concrete cracking group 3 & $56(40-90)$ & $49(0-140)$ & $389(30-640)$ & $112(90-170)$ & $208(160-280)$ \\
Electromagnetic interference & $47(40-60)$ & $15(0-50)$ & $83(0-190)$ & $392(240-810)$ & $535(480-660)$ \\
\hline
\end{tabular}

\section{Comparison with the literature and discussion}

In the literature, it was concluded by Van Steen et al. ${ }^{14}$, Li et al. ${ }^{10}$, and Zheng et al. ${ }^{11}$ that the cracking process was characterised by $\mathrm{AE}$ signals having a higher frequency than AE signals originating from the corrosion process. The results presented in this paper are different from the results observed in the literature.

In Van Steen et al. ${ }^{14}$, small scale cylindrical samples (diameter $36 \mathrm{~mm}$, length $60 \mathrm{~mm}$ ) were tested to allow micro-CT scanning of the samples. The lowest frequency of the cluster containing signals from corrosion was 245 $\mathrm{kHz}$. So, part of the corrosion signals overlap with the observations on the current scale. Note that the frequency filter inside the acquisition system was set between 230 and $850 \mathrm{kHz}$, whereas it was set between 95 en $850 \mathrm{kHz}$ in the current investigation. Lower frequencies will therefore not be captured. Signals caused by mortar cracking showed higher frequencies which is most likely related to the sample scale, resulting in detection of micro-cracking at short sourcesensor distance, and sensor type (broadband sensor up to 850 $\mathrm{kHz}$ ).

Li et al. ${ }^{10}$ obtained three groups based on the peak frequency of the signals. Measurements were performed with 1 sensor mounted on the protruding end of the embedded rebar. All observed groups started from the beginning of the test. Group 1 had signals below $50 \mathrm{kHz}$, group 2 around 110 $\mathrm{kHz}$, and group 3 higher than $240 \mathrm{kHz}$. Group 1 was assigned to the formation of hydrogen bubbles, group 2 to corrosion, and group 3 to concrete cracking. To validate these findings, the paper mainly refers to the work of Yoon et al. ${ }^{4}$ who tested corroded RC beams subjected to four-point bending tests. However, these tests were divided in four different phases in which multiple processes are going on at the same time. Moreover, the ongoing mechanisms may be different from an accelerated corrosion test. $\mathrm{Li}$ et al. ${ }^{10}$ observed a crack on the surface at the end of the test, however, this was not clear from the AE measurements.

Zheng et al. ${ }^{11}$ mainly refer to $\mathrm{Li}$ et al. ${ }^{10}$ and Yoon et al. ${ }^{4}$ to assign damage processes to the observed groups. The difference between the groups is also based on the peak frequency of the signals. Four groups were distinguished: (1) below $30 \mathrm{kHz},(2)$ around $50 \mathrm{kHz},(3)$ around $150 \mathrm{kHz}$, and (4) higher than $200 \mathrm{kHz}$. Group 1 was assigned to variations of the water level (absorption), group 2 to the formation of hydrogen bubbles, group 3 to corrosion, and group 4 to micro- and macro-cracking. Cracking was observed during the experimental program, but had no clear influence on the $\mathrm{AE}$ results (no increase in AE event or AE energy rate).

In order to investigate the effect of a different sensor type, additional dummy samples were tested using a similar sensor as presented in Li et al. ${ }^{10}$ and Zheng et al. ${ }^{11}$, namely 

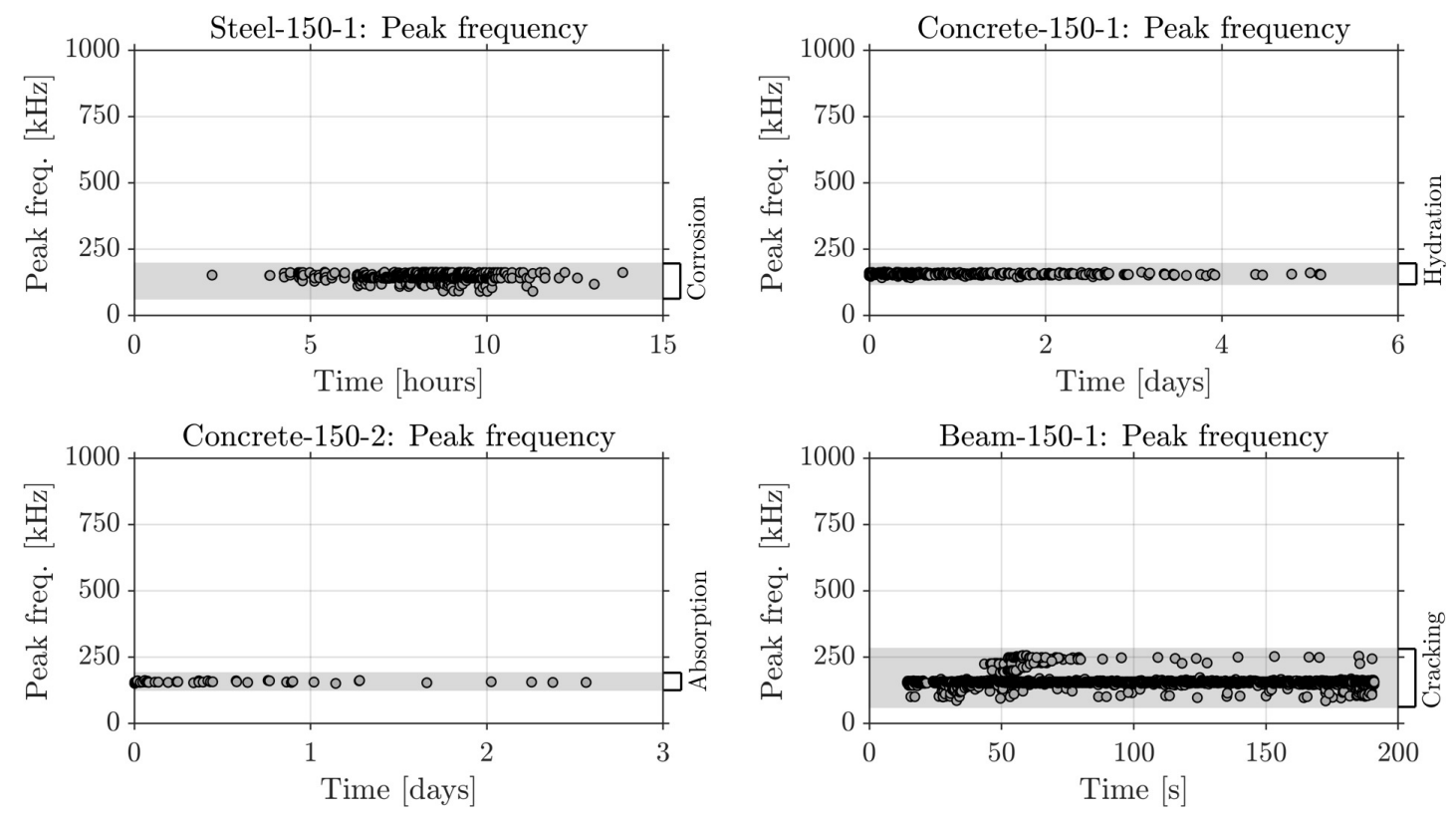

Figure 23. Peak frequencies of $\mathrm{AE}$ signals of dummy samples monitored with $150 \mathrm{kHz}$ resonance sensors.
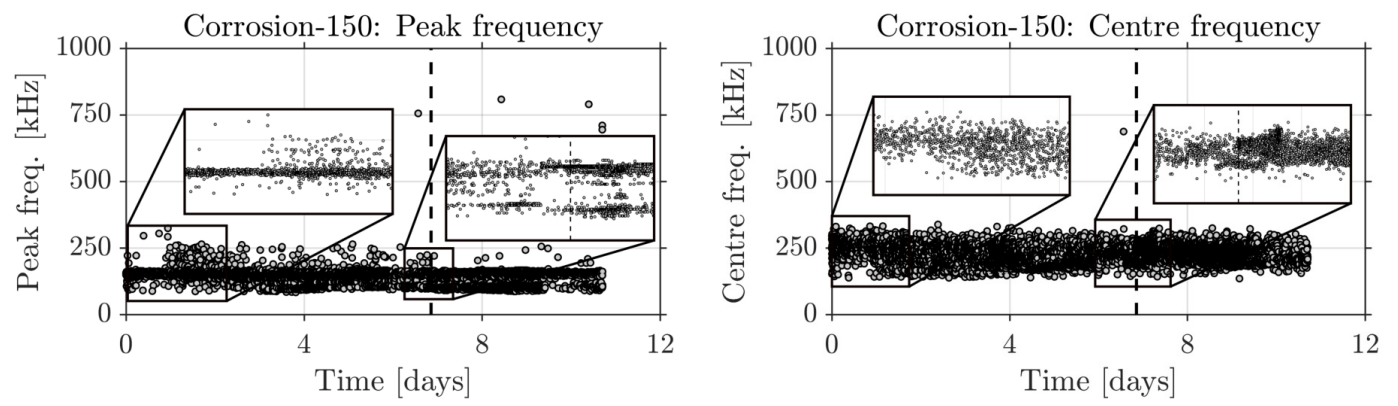

Figure 24. Peak frequencies (left) and centre frequencies (right) of the AE signals captured during an accelerated corrosion test using a $150 \mathrm{kHz}$ resonance sensor.

a resonance sensor of $150 \mathrm{kHz}$. A corroding rebar not embedded in concrete was monitored with one sensor at the end. Dummy samples Concrete 1 and Concrete 2 that were presented in the previous section were also monitored with two $150 \mathrm{kHz}$ sensors with a spacing of $100 \mathrm{~mm}$. A beam was monitored during a three-point bending test with 1 sensor in the middle of its span. The additional dummies will be denoted as Steel-150-1, Concrete-150-1, Concrete-150-2, and Beam-150-1. The peak frequency versus time of each additional dummy sample is shown in figure 23.

It is found that many processes such as corrosion of steel, cement hydration, and absorption have a peak frequency of $150 \mathrm{kHz}$. For concrete cracking, three groups could be distinguished: (1) above $180 \mathrm{kHz},(2)$ around $150 \mathrm{kHz}$, and (3) below $140 \mathrm{kHz}$. These groups respectively correspond to groups 1, 2, and 3 as observed in the previous section. Yet, the group around $150 \mathrm{kHz}$ is much more pronounced due to the use of a $150 \mathrm{kHz}$ resonance sensor.

Additionally, an accelerated corrosion test was performed on an RC prism. Two $150 \mathrm{kHz}$ resonance sensors were placed with a distance of $100 \mathrm{~mm}$ between each other. The corrosion process was accelerated in the same way as the previously described RC prisms. Figure 24 shows the peak and centre frequency of the signals in time. Signals with a peak frequency above $180 \mathrm{kHz}$ can be observed in the beginning of the test meaning that the sample probably started to crack internally. When the crack is visible on the surface, lower frequencies can be observed as was the case for the other samples monitored with broadband sensors.

It can be concluded that the general observations made in the previous sections of this paper remain valid. Processes such as corrosion, absorption and cement hydration are influenced by the sensor sensitivity (flat response with small peak at $220 \mathrm{kHz}$ versus resonance sensor with peak at 150 $\mathrm{kHz}$ ). In all cases, a decrease in frequencies is observed for concrete cracking. Therefore, absolute values of $\mathrm{AE}$ signal characteristics are to be approached with care and sensor sensitivity is to be included in source characterisation and signal analysis, especially when comparing literature data from tests with differing setups. Furthermore, it is recommended to validate $\mathrm{AE}$ source characterisation with other measurements, such as surface cracking.

\section{Conclusions}

This paper focused on the characterisation of different AE sources by monitoring RC samples during accelerated corrosion tests and dummy samples. The approach is applied on two sample scale: RC prisms and RC beams.

For the RC prisms, results show that the moment of concrete cracking can be distinguished from cumulative 
AE events and cumulative AE energy curves, however, the entire history is needed and comparison with crack width measurements is helpful as a uniform threshold cannot be set. The shift in both peak and centre frequency is more clear and can be noticed when the crack reaches the surface. Similar findings were found for the $\mathrm{RC}$ beams.

To characterise the corrosion-induced AE signals, damage sources were assigned based on careful validation with dummy samples in which individual $\mathrm{AE}$ sources were isolated. Based on an analysis of the frequencies of the AE signals recorded in the different dummy samples, it is found that $\mathrm{AE}$ signals from corrosion, absorption, cement hydration, and concrete crack initiation have a peak frequency around $220 \mathrm{kHz}$, which corresponds to a small sensitivity peak for the applied $\mathrm{AE}$ sensors. AE signals originating from concrete macro-crack growth have a distinctly lower peak frequency around $100 \mathrm{kHz}$. As peak and centre frequency ranges for the different $\mathrm{AE}$ sources overlap, also contour maps of the wavelet transforms were presented. The wavelet transform allows to analyse timefrequency characteristics. Still, the distinction between e.g. internal concrete micro-cracking and absorption remains difficult.

To further validate these findings, results were compared with literature data and results from additional tests with a resonance type $\mathrm{AE}$ sensor. The existing literature on characterising $\mathrm{AE}$ signals during corrosion in $\mathrm{RC}$ is still scarce. Other publications have found different frequency ranges for the described damage processes as a different sensor type was used. It can be concluded that the assigned frequency ranges depend on the sensor type and sensor arrangement. Absolute values for AE source characteristics should thus be approached carefully. The validity of the frequency decrease observation upon corrosion-induced concrete cracking was confirmed by the additional tests with resonance sensors.

This is an important step forward towards AE source characterisation of corrosion damage in RC structures. Further elaboration of the current methodology for natural corrosion processes and on-site application is necessary and planned in future work.

\section{Acknowledgements}

This research was performed within the framework of project C24/17/042 "Multi-scale assessment of residual structural capacity of deteriorating reinforced concrete structures", supported by Internal Funds KU Leuven. In addition, the financial support by FWO-Flanders for the postdoc mandate of C. Van Steen (grant nr. 12ZD221N) is gratefully acknowledged.

\section{References}

1. Fédération international du béton (fib). Bulletin 22: Monitoring and safety evaluation of existing concrete structures, 2003.

2. Luo D, Li Y, Li J et al. A recent progress of steel bar corrosion diagnostic techniques in RC structures. Sensors 2018; 19(34): $1-30$.

3. Grosse C and Ohtsu M. Acoustic emission testing - basics for research - applications in civil engineering. Springer, 2008.
4. Yoon DJ, Weiss WJ and Shah SP. Assessing damage in corroded reinforced concrete using acoustic emission. ASCE Journal of Engineering Mechanics 2000; 126(3): 273-283.

5. Abouhussien AA and Hassan AAA. Application of acoustic emission monitoring for assessment of bond performance of corroded reinforced concrete beams. Structural Health Monitoring 2017; 16(6): 732-744.

6. Zaki A, Chai HK, Behnia A et al. Monitoring fracture of steel corroded reinforced concrete members under flexure by acoustic emission technique. Construction and Building Materials 2017; 136: 609-618.

7. Leelalerkiet V, Shimizu T, Tomoda $\mathrm{Y}$ et al. Estimation of corrosion in reinforced concrete by electrochemical techniques and acoustic emission. Journal of Advanced Concrete Technology 2005; 3(1): 137-147.

8. Kawasaki Y, Wakuda T, Kobarai T et al. Corrosion mechanisms in reinforced concrete by acoustic emission. Construction and Building Materials 2013; 48: 1240-1247.

9. Holford KM, Eaton MJ, Hensman JJ et al. A new methodology for automating acoustic emission detection of metallic fatigue fractures in highly demanding aerospace environments: An overview. Progress in Aerospace Sciences 2017; 90: 1-11.

10. $\mathrm{Li} \mathrm{W}, \mathrm{Xu} \mathrm{C}, \mathrm{Ho} \mathrm{SCM}$ et al. Monitoring concrete deterioration due to reinforcement corrosion by integrating acoustic emission and FBG strain measurements. Sensors 2017; 17(657): 1-12.

11. Zheng T, Zhou Y, Zhou Y et al. Localized corrosion induced damage monitoring of large-scale rc piles using acoustic emission technique in the marine environment. Construction and Building Materials 2020; 243: 118270.

12. Suzuki H, Kinjo T, Hayashi $\mathrm{Y}$ et al. Wavelet transform of acoustic emission signals. Journal of Acoustic Emission 1996; 14(2): 69-84.

13. Van Steen C, Verstrynge E, Wevers M et al. Assessing the bond behaviour of corroded smooth and ribbed rebars with acoustic emission monitoring. Cement and Concrete Research 2019; 120: 176-186.

14. Van Steen C, Pahlavan L, Wevers M et al. Localisation and characterisation of corrosion damage in reinforced concrete by means of acoustic emission and x-ray computed tomography. Construction and Building Materials 2019; 197: 21-29.

15. Nasser H, Van Steen C, Vandewalle L et al. An experimental assessment of corrosion damage and bending capacity reduction of singly reinforced concrete beams subjected to accelerated corrosion. Construction and Building Materials 2021; 286: 122773.

16. Hill E, Dassim N, Breckenridge FR et al. Fundamentals of Acoustic Emission Testing, volume 6. American Society for Nondesctructive Testing, 2005.

17. Reda Taha MM, Noureldin A, Lucero JL et al. Wavelet transform for structural health monitoring: A compendium of uses and features. Structural Health Monitoring 2006; 5(3): 267-295.

18. Winkelmans M. Fusie van niet-destructieve onderzoekstechnieken voor corrosiemonitoring in chemische procesinstallaties. PhD thesis. Ku leuven, 2004.

19. Goldaran R, Turer A, Kouhdaragh $\mathrm{M}$ et al. Identification of corrosion in a prestressed concrete pipe utilizing acoustic emission technique. Construction and Building Materials 2020; 242: 118053 